\title{
La lucha por la declaración de emergencia edilicia durante la segunda presidencia de Cristina Kirchner (La Plata, 2011-2015)
}

The struggle for the declaration of emergency of the local public building during the second presidency of Cristina Kirchner (La Plata, 2011-2015)

Romina De Luca*

Resumen: Este trabajo examina la lucha por infraestructura escolar protagonizada por la comunidad educativa en una región de la provincia de Buenos Aires. A partir del trabajo censal, de estadísticas educativas y de los pliegos de obras se reconstruye el cuadro general de crisis de la infraestructura como base material sobre la que emerge un sinfin de conflictos. A partir de diarios locales se reconstruyen las características de los principales conflictos protagonizados por la comunidad escolar y los métodos de acción desplegados.

Palabras clave: Infraestructura escolar, Conflictos Sociales, Comunidad Escolar, Provincia de Buenos Aires, Crisis

Abstract: This paper examines the struggle for school infrastructure carried out by the educational community in a region of the province of Buenos Aires. Based on census work, educational statistics and the bid specifications of schooling construction, the general picture of infrastructure crisis is reconstructed as a material base on which countless conflicts emerge. The characteristics of the main conflicts played by the school community and the methods of action deployed are reconstructed from local newspapers.

Keywords: School Infrastructure, Social conflicts, Educational community, Buenos Aires Province, Crisis

Recibido: 10 enero 2019 Aceptado: 15 marzo 2019

\section{Introducción}

El presente artículo examina la lucha por la infraestructura escolar protagonizada por la comunidad educativa (docentes, estudiantes y padres organizados en post de un objetivo común) en la Región I de la provincia de Buenos Aires. La Región I está conformada por la ciudad capital de la provincia de Buenos Aires, La Plata, y por Berisso, Ensenada, Brandsen, Magdalena y Punta Indio. En este trabajo examinamos un período específico: la segunda presidencia de Cristina Kirchner entre diciembre de 2011 y diciembre de 2015. El trabajo que aquí se presenta forma parte de un estudio mayor

\footnotetext{
* Argentina. Investigadora Asistente del Conicet con lugar de trabajo en IESAC-UNQUI y miembro del CEICS. Docente de la Universidad de Buenos Aires, FFyL materia Historia Argentina 3 cátedra Sartelli. Email: rom.deluca@gmail.com
} 
que investiga la dinámica descentralizada del gasto educativo y la forma que asumen los conflictos vinculados a rubros no salariales en las provincias de Buenos Aires, CABA y Salta entre 2003 y 2015. Se usa el término conflicto social educativo para referirnos a las distintas luchas relevadas. No nos remitimos a lo que podría mejor definirse como conflictos escolares (violencia escolar, conflictos vinculados a discriminación o a las normas de funcionamiento institucional) en los cuales se enfrentan distintos individuos de la comunidad educativa. Utilizamos el término conflicto social educativo para referir a conflictos en los que participan distintos colectivos del ámbito educativo como docentes, trabajadores no docentes, estudiantes, padres enfrentados a las autoridades educativas por aspectos vinculados al plano social de la educación organizados en una lucha común. No nos ocupamos aquí de los conflictos escolares o pedagógicos sino aquellos relacionados con dimensiones de la política pública y presupuestaria.

En este trabajo, se examina el impacto de la ampliación de la obligatoriedad escolar en la demanda de mayor infraestructura, secciones y aulas, así como el reacondicionamiento y la reconversión de escuelas producto de la ampliación de matrícula. Examinamos los reclamos por mayor presupuesto educativo para las escuelas y el crónico deterioro de los edificios escolares, problemas que movilizan a docentes, alumnos, padres, auxiliares, directivos y otros sujetos de la comunidad escolar centralmente en La Plata. Se evalúa el impacto de la dirección sindical en la lucha por mayor presupuesto para escuelas en la región en el período 2011-2015 y las estrategias que se da la propia comunidad para visibilizar su lucha. En el período de referencia, la promoción de la llamada gestión comunitaria aparece como una estrategia oficial para sortear el crónico problema de la infraestructura escolar. Para la reconstrucción del contexto más general, se trabaja con estadísticas educativas, Censos de Infraestructura y se refieren las principales leyes educativas y presupuestarias que rigen en la etapa y las licitaciones de obras publicadas en el Boletín Oficial de la provincia de Buenos Aires. Para la reconstrucción de los conflictos se sistematizan los datos de dos diarios locales: El Día y Hoy. El estudio construye una perspectiva poco transitada para ver un aspecto molecular de la lucha de clases en un territorio cuyo sindicato docente es dirigido por un frente de izquierda.

Los resultados preliminares que aquí se presentan forman parte de un estudio mayor. En general, en materia de conflictividad la historiografía aborda la dimensión de la lucha salarial docente (Auyero, 2002; Palamidessi, 2003; Palamidessi \& Legarralde, 2006, Migliavacca, 2011). La mayoría de los trabajos midieron la conflictividad docente/social general y focalizan en el estudio de las reformas educativas impulsadas por los gobiernos de la región y sus impactos sobre las condiciones (materiales y simbólicas) de trabajo del sector docente y los procesos de sindicalización tendiendo a vincular los conflictos educativos con la emergencia y multiplicación de reivindicaciones sectoriales y colectivas (Auyero, 2002; Farinetti, 1999; Palamidessi, 2003; Loyo 2001; Palamidessi, M., \& Legarralde, M. 2006, Schulman, 2002; Vázquez, 2005; Migliavacca, 2011). Otros autores, examinaron las formas que asume la organización sindical (Suarez, 2005) y la emergencia de nuevos agrupamientos políticos previos y post-2001 de carácter auto-organizado (Gindin, 2008; Migliavacca, 2013), asociado a las centrales sindicales nacionales (Legarralde y Perazza, 2007) o a la consolidación de fracciones de la izquierda como dirección de seccionales o de sindicatos provinciales (De Luca, 2017; Chiappe, M., \& Spaltenberg, R., 2010; Petruccelli, 2005, 2008; Gindin, J., Rodríguez, G., \& Soul, J. 2003; Benclowicz, 2013; Aiziczon, 2010; 2011; 2013; Funes, 2006; Toscano, 2008).

Los estudios sobre conflictividad en general se referencian con aspectos generales de la política educativa y por fuera de ello, se han reconstruido centralmente y en forma independiente los conflictos salariales protagonizados por los trabajadores de la educación. En forma menor, algunos trabajos abordaron aspectos parciales de las reivindicaciones estudiantiles. Los conflictos protagonizados por alianzas de docentes, padres, alumnos y directivos de la comunidad educativa en lucha por reivindicaciones vinculadas a infraestructura, comedores u otros rubros del gasto educativo no destinada a salario todavía no han sido estudiados sistemáticamente. Este artículo se inscribe dentro de una 
investigación mayor que busca suplir esa ausencia a partir de un abordaje dialectico que vincula las trasformaciones estructurales de la sociedad Argentina y su relación con la movilización de la comunidad educativa. Se busca comprender si la fragmentación financiera del gasto y de las distintas autoridades responsables a nivel provincial y distrital guarda algún tipo de relación con la dilución del conflicto en distintas formas territoriales. Se trata de ver la vinculación entre descentralización financiera, focalización del gasto social y su impacto en la lucha y organización de las escuelas. En ese cuadro general, se verá como emerge con fuerza la crisis de infraestructura escolar y la proliferación de protestas vinculadas con ello.

\section{Desarrollo}

El período bajo estudio se encuentra signado por el aumento de la matrícula y el impacto sobre el sistema educativo de la ampliación de la obligatoriedad escolar impulsado por la Ley de Educación Nacional del año 2006 y del correlato en la provincia de la Ley Provincial de Educación No13.688 sancionada en 2007. Tal como dispuso el artículo $16^{\circ}$ de la ley provincial la política educativa asegura la obligatoriedad desde la sala de 4 años del nivel inicial, de todo el nivel primario hasta la finalización de la escuela secundaria "proveyendo, garantizando y supervisando instancias y condiciones institucionales, pedagógicas y de promoción de derechos, que se ajusten a los requerimientos de todos los ámbitos de desarrollo de la educación".

La expansión del sistema educativo se inscribió dentro de los coletazos de una de las mayores crisis económico-político y sociales que sufrió el país: aquella cuyo punto de referencia se ubica el 19 y 20 de diciembre de 2001, proceso que derivó en lo que se conoce como Argentinazo (Sartelli, Eduardo, 2007). El ascenso del kirchnerismo a nivel nacional forma parte de la búsqueda por parte de la burguesía de una recomposición del sistema político en crisis buscando absorber y canalizar las energías sociales que se expresaron detrás de la consigna "que se vayan todos" en las jornadas de diciembre; separar y aislar a las más disruptivas, cooptar a las compatibles con el sistema de dominación. Para desmovilizar a la sociedad post-2001 debía tomar algunas de las demandas de la alianza entre la pequeño-burguesía (coloquialmente denominada en Argentina clase media) y de la clase obrera que se articuló en las jornadas de diciembre y, al mismo tiempo, recomponer coyunturalmente las bases de acumulación devaluación mediante. Previo al ascenso de Néstor Kirchner a la presidencia en 2003, la extensión de los subsidios al desempleo y la devaluación realizada en 2002 recompusieron parcialmente las bases de la economía y desmovilizaron a parte de la clase obrera. La recuperación del precio de la soja y del petróleo a nivel internacional empujaron favorablemente el escenario post-convertibilidad hasta 2008. El proceso de expropiación política requería no solo la emergencia de una figura como árbitro (bonapartismo) sino neutralizar las demandas económicas inmediatas y absorber parte de las demandas políticas de esos sectores centralmente las vinculadas a "derechos civiles" de los sectores pequeñoburgueses (Sartelli, 2007). En efecto, para desmovilizar a la clase media (pequeña burguesía) debía tocar algunas de sus fibras más sensibles. La educación fue (y es) una de sus demandas centrales. También de la clase obrera que, con mayor distancia, percibe que con ella se abre una posibilidad de mejora para sus hijos. Así, el kirchnerismo inició su "transformación" educativa: Ley de Financiamiento Educativo, Ley de Educación Técnico-Profesional, Ley de Educación Nacional, Ley de Educación Sexual Integral. La recomposición económica va a posibilitar la expansión del gasto educativo centralmente vía recomposición salarial docente (recordemos que los docentes fueron uno de los sectores movilizados no solo en el 2001 sino a lo largo de toda la década del '60 con la Carpa Blanca) y la expansión de programas educativos como Conectar Igualdad y el lanzamiento de programas de expansión de infraestructura que, como veremos, se cumplirán muy limitadamente. 
En el territorio de la provincia de Buenos Aires, el correlato directo de ese proceso en materia financiera fue la declaración de la Ley de Emergencia Económica provincial vigente desde el 2002 hasta nuestros días lo que evidencia la profundidad de la crisis estructural no resuelta por la reactivación económica post-2001. También en este recorrido macro para entender las formas que va a asumir la política de gasto en infraestructura en la provincia de Buenos Aires, debemos mencionar la sanción de la Ley 12.858, que entre otras cosas, regula, organiza, reestructura y/o adecua los regímenes regulatorios de servicios públicos de obras sanitarias, provisión de agua corriente y cloacas, e instrumenta nuevas modalidades de gestión a efectos de garantizar su prestación, calidad, eficiencia y la protección de los derechos de los usuarios de acuerdo a la crisis y la ley 13.767 que regula la Administración Financiera y el sistema de Control de la Administración General del Estado Provincial: las prioridades y formas del gasto. Entre otras cosas, habilita al financiamiento municipalizado para la dotación de esos servicios. Como se mostrará esto impactará en la superposición de autoridades (provinciales, locales, municipales) en materia de mantenimiento de los edificios escolares. La emergencia financiera va a chocar con los procesos de ampliación de la matrícula a lo largo de toda la etapa. Resulta necesario, entonces, reponer algunos indicadores generales del sistema educativo en la región bajo estudio. A continuación, se examina la evolución de las unidades educativas (cantidad de escuelas) y matrícula (cantidad de estudiantes).

\section{El gasto en infraestructura escolar}

Durante el 2018, la explosión de una escuela en el Partido de Moreno, provincia de Buenos Aires, y la consecuente muerte de la Vicedirectora y de un auxiliar docente desnudó una situación altamente conflictiva en la provincia: apenas el $1 \%$ del gasto educativo se destina a infraestructura escolar. ${ }^{1}$ Conclusión: las escuelas son un "cromañón" en potencia. ${ }^{2}$ Para el año 2016, Axel Rivas y Daniela Dborkin estimaban que del gasto nacional en educación básica total apenas un 10,7\% se giraba para el desarrollo de programas de infraestructura. ${ }^{3}$ Dentro del gasto provincial total, la cifra era menor: si consideramos el rubro gasto en capital (destinado a construcción y reparación de escuelas y mobiliario) apenas el $4,3 \%$ se gira a la atención de ese rubro mientras el mayoritario $80 \%$ se destina al pago de salarios. ${ }^{4}$ En el período de referencia, en la provincia de Buenos Aires, se observa un aumento del gasto educativo total provincial entre 2003 y 2007, cifra que se mantiene constante o en disminución al 2015. En el 2003, la provincia destinaba el 32\% al gasto educativo si expresamos este último como porcentaje del gasto total. En 2007, la cifra ascendía al 37\%, en 2011 un 38\% y en 2015 un 36\%. Como vemos, esa expansión del gasto guarda relación con la evolución de los precios de la soja y del petróleo y la expansión del superávit fiscal durante esos primeros años, situación que se empieza a revertir luego del llamado "conflicto del campo" (Sartelli, 2008).

\footnotetext{
1Diario El economista, 6/8/2018. En base a informe de IDESA. Disponible online en: https://goo.gl/bXTHdD consultado por última vez el 13/11/2018.

${ }^{2}$ Se refiere al incendio del boliche bailable Cromañón y la muerte de 194 jóvenes, el 30 de diciembre de 2004, en Once, Ciudad de Buenos Aires, Argentina. Se alude a ese hecho porque precisamente Cromañón fue un crimen cuyas causas se desprenden del normal funcionamiento de la sociedad capitalista. Como la educación de masas no es un negocio, se desinvierte en los rubros fijos como infraestructura. El resultado: escuelas que explotan. Por eso, cuando se produjo la explosión de la escuela de Moreno, en agosto de 2018, los sindicatos combativos utilizaron la consigna "basta de escuelas cromañón". Para el hecho del boliche de Once, consúltese: Sanz Cerbino, Gonzalo, Culpable. República Cromañón, 30 de diciembre de 2007, Buenos Aires, Ediciones RyR, 2009.

3Rivas, Axel y Dborkin, Daniela, “¿Qué cambió en el financiamiento educativo en Argentina?”, Documento de Trabajo No 162 , Buenos Aires, CIPPEC, febrero de 2018 p. 27. Los programas de infraestructura incluyen los ejecutados por el Ministerio de Educación Nacional y por el Ministerio del Interior, Obras Públicas y Vivienda.

${ }^{4}$ Idem, p. 29.

Idem, p. 38.
} 
En lo que refiere a la evolución del gasto educativo en la provincia por objeto del gasto, entre 2001 y 2016, se observa que en todo el período el rubro personal (pago de salarios) oscila entre el 78\% y el $84 \%$ del gasto total mientras que las erogaciones de capital (destinado centralmente a infraestructura nueva o reparaciones proveniente de fondos provinciales o nacionales) fluctúa entre $0,4 \%$ del gasto total (como en 2001 y 2002) a 5,1\% en 2011 como pisos y techos. El promedio del gasto en capital, entre 2011 y 2015, fue de 3,54\% siguiendo una curva descendente desde 2011. ${ }^{6}$ En materia de gasto real, las erogaciones en capital, descienden desde 2011 con oscilaciones a 2012 y desde 2013, los gastos caen en forma sostenida. Como se verá, parte de la expansión del gasto en 2012 y 2013, buscó paliar los graves deterioros que distintas tormentas y fenómenos meteorológicos ocasionaron en las escuelas de la región. A pesar de alguna recuperación parcial, entre 2011 y la actualidad la tendencia del gasto en capital resulta claramente descendente.

Gráfico 1. Gasto Educativo de la Provincia de Buenos Aires. Erogaciones en personal y capital. En pesos constantes (2016). 2001-2016

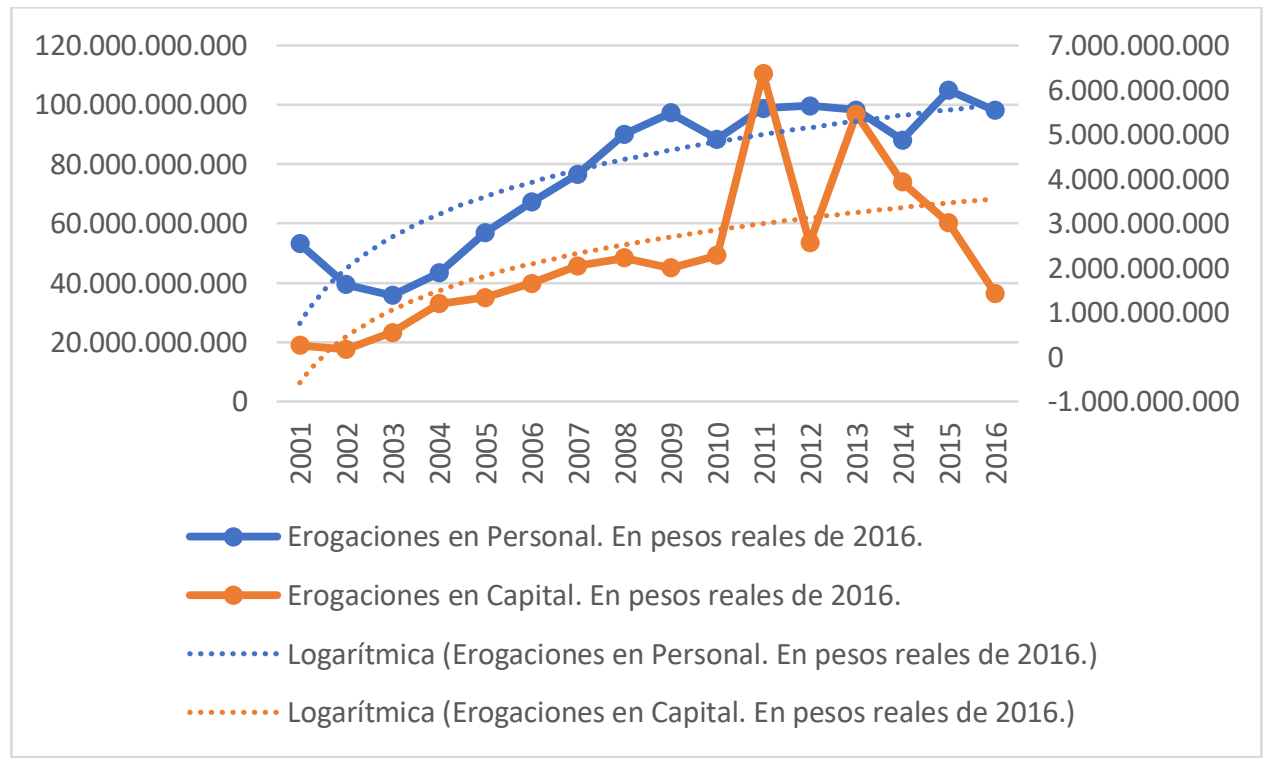

Fuente: Elaboración propia en base a Ministerio de Educación-Coordinación General de Estudio de Costos del Sistema Educativo

Esa tendencia al achicamiento del gasto destinado a capital se expresó en una cantidad menor en la licitación de obras por parte de la provincia de Buenos Aires según se pudo reconstruir gracias a la información publicada en el Boletín Oficial. En efecto, en La Plata, la provincia licitó obras en 2011 para siete edificios escolares. De Refacción General para la Escuela Especial No 518, la Escuela Secundaria No 80 y la Escuela Media No 28, de refacción para la Escuela Primaria $N^{\circ} 25$, para la Escuela Técnica $\mathrm{N}^{\circ} 5$ y para el Jardín de Infantes $\mathrm{N}^{\circ} 902$ y de Terminación y Reemplazo para el Jardín de Infantes $\mathrm{N}^{\circ} 950.7$ A

\footnotetext{
6Provincia de Buenos Aires: Gasto en Educación. Gasto Educativo en la Provincia por Objeto del Gasto. Años 2001-2016. Fuente: CGECSE/DNPPE/SIyCE/Ministerio de Educación de la Nación (ME) en base a ejecuciones presupuestarias provinciales, Dirección de Contabilidad y Finanzas, Dirección de Presupuesto y Dirección General de la Unidad de Financiamiento Internacional/SsCA/ME; Dirección de Información y Estadística de la Calidad Educativa/DNPPE/SIyCE/ME.

7Dirección Provincial de Infraestructura Escolar, Pliego de Obras 2010. Buenos Aires, 2011.
} 
las obras anunciadas en 2011 se sumaban las que se habían licitado durante 2010: la Escuela Media No 16 donde se preveía el reemplazo del edificio. ${ }^{8}$

Para el año 2012, en la Región I (La Plata) se anunciaron inicialmente obras para cuatro escuelas: de refacción para la Escuela Técnica No 8, de refacción general para el Anexo de la Escuela Media $\mathrm{N}^{\circ} 31$, de refuncionalización de la Escuela Secundaria $\mathrm{N}^{\mathrm{o}} 71$ y de restauración y puesta en valor de la Escuela Media $\mathrm{N}^{\circ}$ 33. ${ }^{9}$ En el mes de agosto, también se lanzaron obras para el Instituto Superior de Formación Docente $\mathrm{N}^{\circ}$ 9. En ese mes, se aprobó el pliego para la primera etapa de la construcción de un edificio nuevo. ${ }^{10}$ En el mes de mayo se agregaron obras de refacción en cuatro escuelas: la Escuela Media $\mathrm{N}^{\circ}$ 2, la Escuela Primaria No 130, la Escuela Primaria No 2 y la Escuela Primaria No 3/Escuela Secundaria N $^{\circ}$ 130.11

En el año 2013, se llamó a licitación por obras de construcción para la Escuela Primaria No 11712 y por Licitación Pública $\mathrm{N}^{\circ}$ 44/12, en el mes de enero, se anunció la construcción de un edificio para la Escuela Secundaria No 57 EN Villa Elisa. ${ }^{13}$

Durante el 2015, en el mes de agosto, se convocó a realización de obras para la prevención para emergencias pluviales en la Escuela Graduada Joaquín V. González. ${ }^{14}$ En el mes de noviembre se anunciaron refacciones generales en la Escuela Normal Superior $\mathrm{N}^{\circ} 1.15$

La reducción del gasto en obras de infraestructura va a chocar con una expansión de la matrícula educativa empujada por el aumento de la obligatoriedad escolar en el período bajo estudio. La Región I (La Plata) para 2016 contaba con 1.240 unidades educativas donde estudiaban un total de 313.327 alumnos repartidos en 11.591 secciones. De este total, el sector estatal contaba con 845 unidades educativas, con 223.670 alumnos repartidos en 8.396 secciones mientras que el sector privado registraba un total de 395 unidades educativas con 89.657 alumnos repartidos en 3.195 secciones. En promedio, la dimensión de las escuelas estatales es de 264 alumnos promedio mientras que en las privadas la cifra es de 227 alumnos por unidad educativa mientras que por sección la cifra es de 26,6 es de 28 contando con más alumnos por aula el sector privado.

Siendo esos los datos más generales del año 2016, veamos cómo impactó el aumento de la obligatoriedad en el nivel secundario y en el nivel inicial, es decir, a fin y a inicio del proceso ampliatorio. Comparamos 2007, 2011 y 2016. Vamos a tomar los datos del Distrito La Plata. En 2007, el sector estatal contaba con 125.007 alumnos y el sector privado 72.938 distribuidos en 455 y 376 unidades educativas respectivamente. En 2011, la matrícula ascendía a 141.377 y en el sector privado 75.657 repartidos en 498 y 332 unidades educativas; para el 2016 la matrícula total el sector estatal ascendía a 158.120 y la del sector privado 79.369 alumnos repartidos en 517 y 349 unidades educativas. La concentración de alumnos público-privado por establecimiento es de 275/194, 284/228 y 306/227.16 Tal como puede verse, si bien

${ }^{8}$ Dirección General de Cultura y Educación, Plan de obras 2010-2011. $3^{\circ}$ Publicación de llamado a licitación pública Disposición No 00184/2011, Buenos Aires, 2010.

${ }^{9}$ Dirección General de Cultura y Educación, Plan de obras 2012. Llamado a licitación pública. Disposición N ${ }^{\circ}$ 0004/2012, Buenos Aires, 2012.

${ }^{10}$ Dirección General de Cultura y Educación-Dirección Provincial de Infraestructura Escolar, Plan de obras 2012. Llamado a Licitación Pública. Disposición No 0045/2012, Buenos Aires, 2012.

${ }^{11}$ Dirección General de Cultura y Educación - Dirección Provincial de Infraestructura Escolar, Plan de obras 2012. Llamado a Licitación Pública. Disposición No 0025/2012, Buenos Aires, 2012.

${ }^{12}$ Ministerio de Educación, Dirección de Infraestructura Dirección General de Cultura y Educación UEPPFE Unidad Ejecutora Provincial de Programas con Financiamiento Externo, Plan de Obras. Licitación Pública No 8/13, Buenos Aires, 2013 , p. 1.

13Boletín Oficial de la provincia de Buenos Aires, AÑO CIII. Número 26.983, La Plata, 7de enero de 2013, p. 109.

14Boletín Oficial de la provincia de Buenos Aires, AÑO CVI. Número 27.590, La Plata, 3 de agosto de 2015, p. 6149.

15Boletín Oficial de la provincia de Buenos Aires, AÑO CVI. Número 27.659, La Plata, 10 de noviembre de 2015, p. 9696

${ }^{16}$ Los datos fueron extraídos de Dirección General de Cultura y Educación Dirección Provincial de Planeamiento Dirección de Información y Estadística Departamento Procesamiento de Datos, Matrícula y unidades educativas totales por Distrito, según sector. Serie 2007-2016, Buenos Aires, Argentina, 2017. 
en ambas gestiones se expande, en el sector estatal la concentración de alumnos por escuela resulta mayor. Lateralmente señalamos en relación a este último punto que, la concentración sería mayor si no mediara una "pérdida" de alumnos producto de los elevadísimos niveles de deserción y abandono que afectan centralmente al nivel medio. Hemos señalado cómo ese proceso habla también de las tendencias que operan sobre el sistema y hacen circular a la matricula entre la modalidad común y la de adultos y los circuitos de terminalidad (De Luca, 2017a). ${ }^{17}$ De no mediar esa "circulación" la concentración de alumnos por edificio escolar sería aún mayor y presionaría aún más la crisis por la infraestructura.

Siendo esos los datos más generales, veamos algunas características socioeducativas de la región para luego contextualizar cómo se procesa la crisis de infraestructura escolar y las formas de lucha que protagoniza la comunidad escolar. La Plata cuenta con una población total de 855.079 habitantes. La tasa de menores de 5 años que no asisten a la escuela es de 2,36\%, es decir, poco menos de la mitad que la provincial. En la escuela secundaria, la tasa de repitencia es menor a la provincial $(7,95$ y 9,21 respectivamente). El 8,76\% de la población tiene necesidades básicas insatisfechas. ${ }^{18}$ Según un relevamiento del año 2013 realizado por la ONG Techo ${ }^{19}$, en Argentina se registran 1.834 asentamientos informales ${ }^{20}$ solo en Ciudad de Buenos Aires, provincia de Buenos Aires, Córdoba, Gran Rosario, Alto Valle de Río Negro y Neuquén, Departamento Capital de Misiones y parte de la provincia de Salta. En ellos, habitan unas 532.800 familias. ${ }^{21}$ La provincia de Buenos Aires concentra el $57 \%$ de los asentamientos con 1.024 y el $61,5 \%$ de las familias, con un total de 327.600 aproximadamente. En segundo lugar, se ubica la Ciudad de Buenos Aires, donde si bien el porcentaje de asentamientos es menor (3,1\%), concentra el 13,7\% de las familias, con un total de 73.300. Como si el dato no fuera ya de por sí voluminoso, solo en provincia de Buenos Aires, CABA y Córdoba, 224.379 familias viven en "soluciones habitacionales", eufemismo para denominar viviendas deficitarias que fueron convertidas en viviendas "nuevas" o "mejoradas". 22

En lo que refiere a la relación entre asentamientos y educación, el estudio de TECHO registra que el 13\% de los asentamientos cuentan con una escuela primaria dentro del barrio, el 59\% a menos de un kilómetro, el $24 \%$ entre 1 y $3 \mathrm{~km}$ y el $5 \%$ entre 3 y más kilómetros. Más de la mitad de los jóvenes que asisten a la escuela dentro de los asentamientos denunció haber sufrido robos en el trayecto a ella. ${ }^{23}$ Por eso, la distancia de la vivienda al establecimiento suele ser interpretada como sinónimo de violencia y por ende, podría actuar como un factor de desincentivo a la escolarización. En todo el Gran La Plata, se registran 162 asentamientos con 29.420 familias, de las cuales 23.525 se ubican en la misma ciudad de La Plata. ${ }^{24}$ En general, el 55\% de los asentamientos posee acceso irregular al servicio eléctrico. En La Plata la cifra asciende al $83 \%$. En toda la provincia solo el $11 \%$ de los asentamientos cuentan con acceso a agua corriente de red pública. ¿Cuál es la relevancia de este dato? Consideramos que existe una correlación entre condiciones de vida de la población y ausencia de escolarización lo que implicaría una crisis de infraestructura escolar aún mayor si todos los que no asisten asistieran a la escuela.

En general, se cuenta con poca información sistemática sobre la calidad de las escuelas (características, estado del edificio, conservación, antigüedad, entre otros). Los Relevamientos Anuales

\footnotetext{
${ }_{17}$ De Luca, Romina, Brutos y Baratos. Descentralización y privatización en la educación argentina (1955-2001). Edición aumentada y ampliada, Buenos Aires, Ediciones RyR, 2017a.

18Dirección General de Cultura y Educación-Dirección Provincial de Planeamiento Dirección de Información y Estadística, Descifrando la Región 31 Buenos Aires. Disponible online en: https://goo.gl/Rn5euc

${ }_{19}$ Mayor nivel de detalle se puede encontrar en: De Luca, Romina (2017a)

${ }^{20} \mathrm{La}$ categoría asentamientos comprende villas, asentamientos y barrios populares informales.

${ }^{21}$ TECHO Argentina, Relevamiento de asentamientos informales. Año 2013, Buenos Aires,Techo, noviembre de 2013, p. 26. El informe no contempla en su medición conventillos, edificios tomados, hoteles pensión y conjuntos habitacionales irregulares construidos por el Estado.

22Ibid, p. 28.

23Ibid, p. 50.

${ }^{24}$ Ibid, p. 80.
} 
realizados por el Ministerio de Educación registran indicadores generales vinculados a cantidad de edificios, duración de la jornada escolar, cantidad de alumnos y docentes y aspectos vinculados al rendimiento interno del sistema (promoción, sobre-edad, repitencia, deserción). Solo los Censos de Infraestructura realizados en 1994 y 2014 proporcionan algunos registros sobre el estado general y grado de conservación de los edificios escolares. Veamos, en primer término, qué información brindan.

Como se dijo, en el año 1994, se realizó el primer Censo de la Calidad Edilicia de los edificios escolares cuyos resultados se ampliaron en 1998. El Censo partía de una consideración clara sobre la pertinencia de conocer el estado de las escuelas y su mobiliario. No se trataba solo del recurso físico básico de las actividades educativas, sino que también eran "uno de los factores que intervienen en el proceso escolar, entendido éste como la instancia fundamental del sistema en el cual se interrelacionan sus actores, se produce el servicio educativo y se gestan resultados". Ya previamente, la UNESCO y el BID habían advertido sobre la correlación entre infraestructura escolar y rendimiento.

Durante el año 1998, se realizó en todo el territorio un Censo Nacional de Infraestructura Escolar (CENIE) y se relevaron las condiciones de infraestructura de los edificios. ${ }^{25}$

En toda la provincia de Buenos Aires, para 1998, se registraban un total de 11.158 edificios escolares, 8.001 estatales y 3.157 de gestión privada. La mayoría eran utilizados por un único establecimiento (7.504) mientras casi el 33\% eran de uso compartido (3.636). El 80\% disponía en su entorno (en un radio de un kilómetro a la redonda) de acceso al transporte público, situación que equivale a considerar que el 20\% no lograba acceder a esa vía de comunicación fundamental con la consecuente dificultad de acceso para la comunidad educativa. En las escuelas privadas, el acceso a medios de comunicación trepa al 95\%. En las escuelas estatales sobre un total de 7.359 edificios escolares, el 45\% no contaba con gas natural ni servicio de agua de red, el $62 \%$ no tenía servicio cloacal, el $60 \%$ carecía de desagües pluviales, lo que va a generar un gran caos en las escuelas durante el año 2013 como se verá y el $28 \%$ no contaba con servicio de recolección de residuos lo que genera focos infecciosos en las escuelas. ${ }^{26} \mathrm{El} 7 \%$ de los establecimientos estatales no disponían de un servicio de salud o de esparcimiento en el radio de un kilómetro a la redonda. El 35\% se encontraba emplazado en un entorno donde existía riesgo ambiental a 500 metros a la redonda. ${ }^{27} \mathrm{La}$ amplia mayoría no contaba con instalaciones aptas para alumnos con discapacidad (más del $70 \%$ ). De los que sí tenían algún tipo de adaptación para discapacitados motores, la amplia mayoría disponía de rampas para su acceso (77\%) lo que implica un esfuerzo manual para el acceso de los alumnos a las escuelas. El 10\% de los establecimientos de la provincia, disponía de instalaciones contra incendios lo que convertía a esas escuelas en un "Cromañón" en potencia.

En lo que refería a la calidad de los edificios, más del $68 \%$ de las aulas comunes fueron catalogadas como "muy pequeñas" y otro $25 \%$ como "pequeñas" lo que marca la pauta de hacinamiento que regía en la provincia de Buenos Aires. El 11\% fueron declaradas en estado de conservación malo y regular. Poco menos de la mitad de las escuelas contaban con patio abierto y solo un tercio patio cubierto. Solo el 35\% de las escuelas tenían "sala de profesores" ya sea para el descanso o la reunión de personal y número similar de escuelas disponía de un espacio adecuado para el comedor de alumnos.

El censo de Infraestructura se repitió entre 2009 y 2014. Se convocó en 2008, a través de la Resolución $\mathrm{N}^{\circ}$ 54/08 del Consejo Federal de Educación. Los datos publicados son solo una muestra28 pero daban cuenta que sobre un total de 5.584 predios escolares se registraban 8.979 edificios escolares,

25DINIECE, Censo Nacional de Infraestructura Escolar. Los edificios escolares del país en 1998 Resultados definitivos del CENIE 98 , Buenos Aires, Ministerio de Educación, diciembre de 2004.

26DINIECE, Censo Nacional op. cit, p. 32.

${ }^{27}$ Sobre el total de 3.899 establecimientos, 1591 se encontraban próximos a basurales, 391 a mataderos, 2.404 próximos a depósitos de sustancias inflamables o explosivas, 836 a fábricas contaminantes y 224 próximos a cárceles.

28Ministerio de Educación, Censo Nacional de Infraestructura Escolar. Jurisdicción Buenos Aires, 30 de marzo de 2017. Informes disponibles en: http://cenie.educ.ar/ 
a razón de 1,6 establecimientos por predio. Aunque también se registraban predios no escolares (no era esa su principal actividad) donde se habían emplazado 596 edificios escolares. El 15,5\% de las construcciones contaban con techos de estructura metálica y el 38\% de madera; el 1,1\% respondía a una construcción de tipo "prefabricada". El 96\% tenía paredes de ladrillos. En materia de terminaciones de las paredes, el 27\% tenía revoque a la cal, el 10\% ladrillo, el 1\% chapa. El 40\% de las escuelas no disponían de desagüe cloacal, un $25 \%$ carecía de agua a través de servicio de red y casi el $20 \%$ no tenía gas de red, un $5 \%$ no disponía de servicio de recolección de residuos, casi un $5 \%$ carecía de alumbrado público, un $34 \%$ no contaba con desagüe pluvial. Además, el 52\% carecía de salidas de emergencia, apenas el 28\% tenía luz de emergencia y un plano de evacuación, un 32\% contaba con algún sistema de señalización. Casi la mitad de las escuelas disponía de alarmas antirrobos. En lo que refiere a vulnerabilidad y contaminación, el 15\% se encontraba próximo a basurales o zonas de rellenos, el 5\% a mataderos, más del 18\% a depósitos de sustancias inflamables, casi el $22 \%$ cercano a algún foco contaminante, el 15\% a un tendido de alta tensión o de una autopista o camino altamente transitado, el 32\% estaba en zona inundable y el $21 \%$ próximo a napas contaminadas. Poco más de la mitad $(52 \%)$ tenía patio exterior.

Tal como puede verse, un número sustantivo de los establecimientos de la provincia continuaba con graves problemas de infraestructura. A pesar del incremento en los gastos de capital posibilitados por la recaudación récord sobre los precios de soja y petróleo, por lo menos, un $40 \%$ de las escuelas carece de cloacas, un 34\% de las escuelas no tienen desagües pluviales, un $25 \%$ no tiene agua de red y un $20 \%$ no tiene gas de red, situaciones que cómo veremos se agravarán además en las escuelas que sí cuentan con los servicios por la falta de mantenimiento de las instalaciones. En segundo lugar, insistimos con un señalamiento ya hecho: los datos censales de 2009/2014 son apenas una muestra. Por eso, a la luz de los hechos que vamos a describir en los próximos acápites creemos que más que una mejora en las condiciones edilicias los datos censales evidencian un deterioro más o menos consolidado. Ese cuadro se agrava si se considera el uso más intensivo de los establecimientos (aumenta la cantidad de unidades escolares y la concentración de alumnos en ellos) tal como vimos en párrafos anteriores. Esa es la base material sobre la que se desarrollará una gran conflictividad en materia edilicia tal como se mostrará en el próximo acápite.

\section{Ampliación de la obligatoriedad y lucha por infraestructura escolar}

En este apartado, vamos a reconstruir los principales conflictos vinculados a infraestructura escolar que se sucedieron entre fines de 2011 y fines de 2015 en la región bajo estudio. Se trata de examinar el período que se corresponde con la segunda presidencia de Cristina Kirchner a nivel nacional y la gobernación de Daniel Scioli en la provincia de Buenos Aires. En términos generales, la etapa bajo estudio está marcada por el deterioro general de la economía y, con posterioridad, al conflicto con el campo en el 2008, la construcción de lo que se conoce como "relato": la forma en la que el régimen justificó su ascenso como una fuerza supuestamente progresiva, es decir, la formación ideológica kirchnerista. La política de derechos humanos, la "renovación" de la Corte Suprema de Justicia, el nacionalismo, la política de medios (Ley de Medios y construcción de una mirada autista sobre los medios opositores tildados de "enemigos"), la ampliación del sistema de subsidios y la educación jugarán un lugar central en la argamasa ideológica del kirchnerismo (Sartelli, 2017). En materia económica, toda la etapa kirchnerista (2003-2015) estuvo marcada por la expansión de las actividades terciarias (vinculada a servicios). El aumento de la productividad fue de la mano de una menor proporción de obreros por unidad de producto, del crecimiento del empleo estatal a partir de 2007 representando el 36\% de los ocupados en Río Gallegos; el 33,5\% en Viedma; el 22\% en Gran La Plata; y el 24\% en Posadas. Cierto es que históricamente, el empleo estatal ha tendido a incrementarse en la Argentina como forma de contención a la sobrepoblación relativa (Sartelli, Harari, Villanova, 2019 en prensa). La consolidación del 
empleo no registrado (degradación de las condiciones contractuales y salariales de los trabajadores) en torno al 35\% también marca el período específico que aborda este artículo y con ello el deterioro del nivel salarial de esos trabajadores. Mientras que en 1974 los trabajadores no registrados percibían en promedio un 34\% menos que los registrados, en 2015 esa diferencia fue de 51\%, es decir, en cuatro décadas, la brecha se incrementó 17\% (Sartelli, Harari, Villanova, 2019 en prensa). Esa caída afecta al nivel salarial del conjunto de los trabajadores. Entre 1974 y 2015 el promedio salarial de los trabajadores ocupados descendió un $47 \%$. Es decir, se ubica prácticamente en la mitad. Desde comienzos de los 90, el nivel salarial ha tendido a mantenerse dentro de una misma franja, con una caída pronunciada entre 1999 y 2003 del 31\%, tras lo cual vuelve a recuperarse lentamente para alcanzar en 2009 el nivel de 1993, el mayor hasta ese momento. Luego se produce un ascenso del 10\% hasta 2013, tras el cual comienza una nueva caída del 13\% hasta 2015. La docencia no es la excepción, aunque su curva descendente se inicia en los años cuarenta con salarios que se ubican a un tercio, en capacidad de compra real, de los de la década del '30 (De Luca, Sartelli y otros: 2017). A ese cuadro, se agregan las cifras de pobreza estructuralmente consolidada que hacia 2014 alcanzó cifras cercanas al 36 \% (Perfil, 2014) mientras el desempleo real se ubicaba cercano al $28 \%$ (Infobae, 2015). Todos estos son algunos de los indicadores de una realidad más o menos palpable: bajo este sistema social la Argentina va camino a su descomposición (Sartelli, 2011). Las crisis se suceden y las "recuperaciones" son episódicas. Como se mostrará en este apartado, la crisis de la infraestructura escolar es el corolario lógico de ese proceso. A continuación, en base a la información recabada de dos diarios locales (Diario El día y Diario Hoy) se describen los principales conflictos. Existe una cifra "negra" que los diarios no registran, por lo dicho, se

advierte que la conflictividad puede ser aún mayor para la etapa de referencia. Pese a ese déficit en el registro, los datos muestran que en La Plata, los conflictos por la infraestructura escolar se colocaron a la orden del día durante el período 2011-2015. En otros trabajos, se reconstruyeron períodos previos (De Luca, 2018).

\section{Año 2011}

Desde el mes de mayo, la Escuela Secundaria No 71 se encontraba reclamando la construcción de un nuevo edificio. Producto de la movilización de la comunidad educativa, las autoridades prometieron en el mes de agosto el inicio de la construcción de una nueva escuela, pero en octubre aún aguardaban por el inicio de obras. La protesta logró visibilizar el conflicto. Entre otras acciones, la comunidad escolar decidió realizar el acto escolar del 25 de mayo en plena calle.

Una situación similar era la de la Escuela Secundaria No 7 de Arturo Seguí. Desde 2008 reclamaba por la construcción de un edificio nuevo que permitiera albergar a los más de 400 alumnos de la institución. Por falta de espacio, los docentes dictaban clases en el pasillo tal como denunciaron cuando, junto a padres y estudiantes, decidieron movilizarse a la calle. La escuela protagonizó toda una serie de protestas durante ese año para intentar arribar a una solución.

También durante ese año, muchas escuelas denunciaban que eran objetivo crónico del vandalismo. Entre otras, durante 2011 se movilizaron las Escuela No 62, la Secundaria No 14, la Especial $\mathrm{N}^{\circ} 529$ (173 entre 521 y 522); Primaria No 116, Media $\mathrm{N}^{\circ} 59$ y de Adultos $\mathrm{N}^{\circ} 724$ (146 y 59); Jardín de Infantes $\mathrm{N}^{\circ} 906$ (63 entre 21 y 22) y Jardín $\mathrm{N}^{\circ} 904$ (78 y 185). El vandalismo fue un problema que signó tanto el año 2011 como anteriores y posteriores. Solo en el 2011 se registraban por lo menos 36 escuelas vandalizadas. Aquí solo señalaremos que estos hechos, que requieren un estudio específico, ponen de relieve una ruptura del vínculo entre las escuelas atacadas y la comunidad escolar.

En otro orden de problemas, durante el 2011, emergieron una cantidad de casos de violencia escolar y solo la mitad de las escuelas secundarias contaban con equipos de orientación (gabinetes) según los datos oficiales. Si bien la Ley de Educación Nacional estipulaba que cada escuela contaría con su 
propio equipo, la realidad estaba muy lejos de cumplirse en la provincia de Buenos Aires. Inclusive, a inicios del 2018, la gobernadora de la provincia María Eugenia Vidal estipulará que dada la ausencia de equipos por escuela los pocos existentes pasarían a atender a nivel distrital.

Año 2012

Durante el año 2012, en el mes de enero, el Consejo Escolar platense advertía que destinaría $500.000 \$$ a afrontar reparaciones ocasionadas por ataques vandálicos a escuelas pero que la cifra era insuficiente. ${ }^{29}$ Por eso, el Consejo Escolar realizó una comparación para ponderar el nivel de daño. Estimaban que, con esa suma, "se hubiesen podido comprar y colocar 716 estufas, o bien se habría podido equipar a 136 colegios con equipos de audio y video, así como reparar y acondicionar 107 baños". El informe se publicó a propósito de un acto vandálico en tres escuelas: las Primarias $\mathrm{N}^{\circ} 11$ y 50 y en el Jardín $\mathrm{N}^{\circ} 909$.

A fines de febrero, se reconocía que el deterioro de los edificios escolares era una de las principales causas de pérdida de días de clase. Como forma descentralizada de colaboración y control, la Facultad de Arquitectura de la Universidad Nacional de La Plata se ocuparía de relevar el estado edilicio de los 1.837 predios escolares bonaerenses, donde se alojaban más de 3.000 establecimientos educativos. Tal como señalaban: "uno de los objetivos principales de este censo es estimar con mayor rigor la necesidad de obra nueva y su localización, así como detectar los espacios disponibles para ampliar la obra existente. En función de atender los requerimientos de la extensión de la escolaridad obligatoria, se tendrán en cuenta las condiciones de seguridad, de accesibilidad, de circulación, ventilación y acondicionamiento térmico." 30

Uno de los conflictos por infraestructura más largos de la etapa se iniciaría en la Escuela de Danzas tradicionales cita en calle 7 y Plaza Rocha. El 4 de abril la escuela fue clausurada por la Dirección de Educación dados los problemas edilicios del establecimiento. La escuela de estética que funcionaba en el mismo predio había sufrido desprendimiento del cielorraso durante el horario escolar. ${ }^{31}$

A su vez, el temporal de abril de 2012, expondrá la situación precaria de las escuelas: 100 establecimientos debían ser atendidos por los Consejos Escolares para ser puestos en uso, 40 más solo habían sufrido daños relativamente menores y otros 40 requerían intervención provincial para su restablecimiento cuyos arreglos demandarían más de un mes. ${ }^{32}$ En el largo conflicto, alumnos, docentes y padres, organizaron permanencias, actividades artísticas, clases públicas, asambleas. En el contexto de movilización de la escuela, se conocieron los datos de la Agencia de Recaudación platense sobre infraestructura escolar: así detectó que de los 74 centros educativos relevados y en regla, 14 tenían problemas de seguridad edilicia en su interior. Entre las irregularidades más recurrentes se pudo observar la falta de mantenimiento de matafuegos; sistema de la alarma que detectara incendios; ausencia de plan de evacuación; puertas de emergencia bloqueadas, falta de señalización adecuada; desarreglos en la instalación eléctrica y de gas, y otros detalles de infraestructura edilicia. ${ }^{33}$ Algo que, como se vio, los Censos nacionales de Infraestructura también verificaban. No era la primera vez que la Escuela de Danzas estaba movilizada por problemas edilicios. Precisamente por eso, frente a la falta de respuestas, los alumnos decidieron tomar el edificio de la escuela en el mes de junio. $\mathrm{Al}$ mes siguiente, la escuela de Teatro se plegó a la protesta y procedió también a la toma.

${ }^{29}$ El día, 19/1/2012.

${ }^{30} \mathrm{El}$ día $27 / 2 / 2012$.

${ }^{31}$ El día 4/4/2012, 13/4/2012.

${ }^{32}$ El día $9 / 4 / 2012$.

${ }^{33}$ El día 5/5/2012. 
En el mes de mayo, la Escuela Media $\mathrm{N}^{\circ} 9$ de Olmos realizó una sentada como forma de protesta a la ausencia de un plan de obras prometido en 2010 para resolver una situación estructural: más de 700 alumnos distribuidos en tres turnos compartían el único baño con el que contaba la escuela. ${ }^{34}$

En el mes de junio, varias escuelas, entre las que se encontraba la Escuela $\mathrm{N}^{\circ} 15$, iniciaron protestas y sentadas por la falta de calefacción en sus edificios. ${ }^{35}$ En el transcurso del mes, organizaron una movilización a la sede de educación de la provincia para reclamar la finalización de las obras en su colegio, el cumplimiento del plan Conectar Igualdad y por buffets con precios accesibles, entre otros puntos.

En el mes de julio, la Escuela Secundaria $N^{\circ} 63$ de 522 y 118, de Tolosa, se movilizó para presionar por que se cumpliera con la creación de un edificio nuevo para esa escuela prometido en el año 2009.36 Previamente habían juntado firmas para presionar a las autoridades.

\section{Año 2013}

Un informe del Consejo Escolar platense registraba más de 70 acciones de vandalismo en escuelas platenses. ${ }^{37} \mathrm{Al}$ inicio del ciclo escolar, grupos de padres de la Escuela Normal 1 denunciaban que muchos alumnos no podían sentarse por falta de bancos y contabilizaban un déficit de, por lo menos, 175 mesas y sillas. En esa oportunidad, ATE Ensenada denunciaba que no se trataba del único caso local y adicionaba la baja cobertura de cargos auxiliares que también obligaba a las escuelas a brindar un servicio reducido. ${ }^{38}$ Por su parte, la directora de la Escuela $N^{\circ} 60$ declaraba que hacía años que reiteraba el mismo pedido: "necesito 15 bancos dobles, 30 sillas, un armario y pizarrones para el ciclo lectivo que empieza. Todos los años renuevo el pedido, pero desde hace dos no llega nada y son muchas las escuelas que atraviesan una situación similar. Me faltan cosas como para equipar tres aulas, pero si me llegara lo suficiente para completar una estaría conforme". ${ }^{39}$

Se trataba de un problema extendido. Muchas escuelas denunciaban la falta de mobiliario. Ese no era el único inconveniente: la crisis de infraestructura era extendida y profunda en la región. La Plata aparecía en la lista de distritos en emergencia edilicia junto a Lanús, La Matanza, Quilmes, Moreno, José C. Paz, Varela y Almirante Brown. En los barrios periféricos las escuelas se encontraban desbordadas, superpobladas, al punto que informes locales realizados por el sindicato hablaban de un faltante del orden de 23 escuelas en el Gran La Plata (13 secundarias, 3 especiales y 7 jardines). No solo faltaban escuelas, también aulas: el sindicato contabilizaba un déficit de 71 aulas a construir para atender a la matrícula existente (38 para secundarias, 17 para el nivel inicial, 13 para primarias y 3 para escuelas especiales). La emergencia contemplaba además la numerosa cantidad de escuelas que necesitaban reparaciones importantes en sus baños o en otras partes vitales del edificio. ${ }^{40}$

Los primeros días de marzo, el Jardín de Infantes № 909 de Los Hornos pedía autorización para dar inicio al ciclo lectivo en la sociedad de fomento local debido al deplorable estado del edificio donde funcionaba la escuela. No se trataba de problemas menores: un grupo de padres relataba que existían rajaduras estructurales y graves filtraciones en la cubierta que provocaba la inundación de todas las salas

${ }^{34} \mathrm{El}$ día 5/5/2012.

${ }^{35} \mathrm{El}$ día 13/6/2012.

${ }^{36} \mathrm{El}$ día $1 / 7 / 2012$.

${ }^{37} \mathrm{El}$ día 26/11/2013. Disponible online en https://goo.gl/oXsXoA

${ }^{38} \mathrm{El}$ día 28/2/2013. Disponible online en https://goo.gl/7WSQKV

${ }^{39} \mathrm{El}$ día 17/2/2013. Disponible online en https://goo.gl/EeM2ys

${ }^{40} \mathrm{El}$ día 16/1/2013, 17/2/2013. Para economizar las citas, de aquí en más, se referencian todos los diarios donde aparecen los conflictos, pero se deja el link digital de la última fecha mencionada. Disponible online en https://goo.gl/pfhc7s 
cada vez que llovía. Como su fuera poco, persistían los problemas de falta de agua y en los baños. ${ }^{41} \mathrm{El}$ jardín 901 también narraba una serie desprendimientos de la mampostería de techos y paredes.

En el mes de abril, el Consejo Escolar platense concluía que no podía mantener en condiciones a todas las escuelas de la región. Se trataba del relevamiento de costos reales para el mantenimiento de las escuelas en base a las necesidades recabadas en un relevamiento de 50 escuelas sobre las más de 309 de ciudad. ${ }^{42}$ Mientras tanto, la Escuela $N^{\circ} 45$ denunciaba que su edificio se encontraba con riesgo de derrumbe. Si bien la Unidad Ejecutora negaba tal situación encaminaba un plan de obras para la construcción y reparación de cloacas, desagües pluviales, cubiertas de chapa, cielorrasos, la cubierta del SUM y la instalación eléctrica. ${ }^{43}$ La tormenta registrada los primeros días de abril que dejó un saldo de 54 muertos oficiales en la ciudad agravaron un cuadro ya de por sí desesperante: el sindicato declaraba que más del $70 \%$ de las escuelas se encontraba en emergencia edilicia. ${ }^{44}$ De esas, casi el 10\% se encontraban en estado crítico. Muchas de las escuelas habían registrado más de un metro de agua en el interior de los edificios. Por ejemplo, la Escuela 56 Almafuerte se declaraba directamente como una "escuela destruida" tal como rezaba un cartel en la puerta del establecimiento. La Media 1, la Primaria 33, la Primaria 102 y la Técnica 8 corrieron una suerte similar. ${ }^{45}$

En el mes de mayo se produjo una fuga en la escuela Normal $\mathrm{N}^{\circ} 1$ y los alumnos debieron ser evacuados. La falta de gas era un problema crónico. ${ }^{46}$ En otro trabajo nos hemos referido a ello para el período 2003-2007. No era la única con problemas. Una madre denunciaba que su hija, junto a la docente, habían sufrido descompensaciones por problemas en las cloacas de la escuela $\mathrm{N}^{\circ} 73$ a la que concurrían, en calle 140 y 44, en San Carlos. En tanto, en un jardín de Los Hornos, de 140 y 63, tenían problemas con el cielorraso. Un grupo de padres de la Escuela $\mathrm{N}^{\circ} 45$ se había movilizado reclamando por obras en el edificio. A principios de mes, los Sutebas opositores ${ }^{47}$ de La Plata, La Matanza, Florencio Varela, Moreno, San Martín, Hurlingham, José C. Paz y Lanús exigieron antes la Dirección Provincial de Infraestructura por la situación de riesgo en varias escuelas y reclamaron por la ejecución inmediata de todas las obras que fueran necesarias. Refacciones, ampliaciones, construcciones y la provisión de mobiliario fueron algunas de las demandas concretas. ${ }^{48}$ Cabe destacar que la ciudad de La Plata era uno de los ocho distritos con mayor cantidad de escuelas en emergencia edilicia.

Durante el mes de junio, los alumnos de la Técnica $\mathrm{N}^{\circ} 8$ (ubicada en calle 7 y 526 ) realizaron un corte de calle para reclamar por el estado del edificio escolar. A sus demandas sumaban la implementación de las prácticas profesionalizantes en el séptimo año de cursada y por la implementación del plan Conectar Igualdad. ${ }^{49}$ Como resultado de la protesta, se hicieron presentes para escuchar los reclamos el Presidente del Consejo Escolar y el director de Infraestructura para ver los baños y establecer plazos de una futura. ${ }^{50}$ Previamente, la Secundaria No 10 había reclamado por el "deplorable" estado de su edificio escolar y la Secundaria $\mathrm{N}^{\circ} 40$ reclamaba por un edificio propio. Estos últimos realizaron un corte de calle en Ruta 36

${ }^{41} \mathrm{El}$ día 1/3/2013, 2/3/2013, 6/3/2013. Disponible online en https://goo.gl/hQLLek

${ }^{42} \mathrm{El}$ día 20/4/2013. Disponible online en https://goo.gl/zKN2oS

${ }^{43} \mathrm{El}$ día 18/4/2013. Disponible online en https://goo.gl/4PDQsB

${ }^{44 E l ~ d i ́ a ~ 3 / 4 / 2013, ~ 4 / 4 / 2013, ~ 6 / 4 / 2013, ~ 9 / 4 / 2013, ~ 10 / 4 / 2013 . ~ D i s p o n i b l e ~ o n l i n e ~ e n ~ h t t p s: / / g o o . g l / 3 Q 5 X s h ~}$

${ }^{45} \mathrm{El}$ día 5/4/2013. Disponible online en https://goo.gl/vwLDvV

${ }^{46}$ Diario Hoy, 22/5/2013.

${ }^{47} \mathrm{Se}$ refiere a los sindicatos que son dirigidos por distintas fuerzas de izquierda unidas en un frente que se conoce como Multicolor. Para la dinámica política de esos sindicatos en Buenos Aires se remite a otro trabajo. De Luca, Romina, "La izquierda en docentes. Entre el crecimiento de la Multicolor y el seguimiento a la celeste", Razón y Revolución, Número 30, Buenos Aires, Ediciones RyR, 2017, 73-104.

${ }^{48} \mathrm{El}$ día 3/5/2013. Disponible online en https://goo.gl/S3ABp8

${ }^{49}$ Se trata de distribución de netbooks para alumnos y docentes en comodato gratuito. Las escuelas de adultos fueron excluidas del programa.

${ }^{50} \mathrm{El}$ día 28/6/2013. Disponible online en https://goo.gl/1cRTzW 
y 492.51 También los primeros días del mes, un grupo de estudiantes secundarios nucleados en la CUES (Coordinadora de Estudiantes Secundarios) se había manifestado frente al edificio central de Educación, con un corte de calle, para reclamar por las condiciones edilicias de las escuelas Normales 1, 2 y 3, como así también de las escuelas técnicas y otros colegios de la Región, incluidos Berisso y Ensenada. ${ }^{52}$

Durante el mes de julio, padres y alumnos de la Escuela Secundaria $\mathrm{N}^{\mathrm{o}} 3$ realizaron un corte de calles reclamando un edificio propio. La escuela venía funcionando en dos escuelas distintas: la Media $\mathrm{N}^{\circ}$ 20 y la Secundaria $\mathrm{N}^{\circ} 17.5^{3}$ La solución provisoria de traslado afectaba seriamente la cursada: no se dictaban clases de educación física, tres divisiones cursaban juntas en simultáneo, la jornada escolar había sido reducida. La Inspección local llamaba a los padres a tener paciencia: había dieciséis obras en marcha incluida la de la escuela $\mathrm{N}^{\circ}$ 3. Desde abril se registraban las irregularidades por eso, un grupo de padres y alumnos, junto a docentes, decidieron realizar un piquete frente a la escuela.

Por su parte, una numerosa cantidad de escuelas denunciaban cursadas en condiciones de hacinamiento. Tal era el caso de la Escuela 59 de villa montoso, la 236 de 7 y 601, la 125 de barrio jardín, donde convivían un jardín y una secundaria.

Durante el mes de agosto, los alumnos de la Escuela Secundaria No 89 de Tolosa, junto a un grupo de padres, realizaron un piquete en la calle 520 reclamando por la falta de agua que afectaba al edificio, los reiterados cortes de luz y el pésimo estado del edificio. En particular, remarcaban que los baños de la escuela se encontraban en situación deplorable. ${ }^{54}$ Previamente se habían movilizado a la sede de Educación alumnos de los Institutos de Formación Docente 8, 9 y 95 y de las escuelas de danzas tradicionales, de teatro y de danzas clásicas para reclamar por el estado de sus escuelas. Los alumnos entregaron a las autoridades un petitorio con cada uno de los reclamos. 55 También se movilizaron los alumnos de la Escuela Secundaria N ${ }^{\circ} 16$ de Los Hornos (conocida como Escuela El Túnel) reclamando por la paralización de las obras de refacción del edificio. La comunidad educativa planeaba realizar también un "abrazo" a la escuela como medida de protesta ya que hacía más de un mes que aguardaban una respuesta oficial por la parálisis de las obras. Los alumnos debían ingresar a la escuela por un túnel de acceso (de allí su nombre), al mismo tiempo se dictaban clases en cinco aulas de chapa y los más de 800 alumnos junto a directivos, docentes y auxiliares compartían un único baño. Como si fuera poco, denunciaban filtraciones en los sectores de obras y accesos lo que obligaba a suspender las clases cada vez que llovía. ${ }^{56}$

En el mes de septiembre se anunciaron obras para distintas escuelas. En primer lugar, la licitación del nuevo edificio para la Escuela Primaria 30 de Tolosa. El "Plan Mejora" alcanzaría a las escuelas técnicas 1, 4, 5, 6 y 7, a la escuela agraria Alejandro Korn; a los centros de formación profesional 402, 408, 413, 419 y 425; la Escuela Colonia Las Rosas; la Escuela de Teatro Nº 4; el Centro de Formación Laboral N ${ }^{\circ}$ 3, y el Instituto Superior de Formación Técnica $N^{\circ} 6012 .{ }^{57}$ También en este mes, cerca de sesenta y seis colegios demandaron la cobertura de los cargos auxiliares vacantes lo que obligaba a muchas de ellas a prestar una jornada reducida. Tal era el caso de la Escuela de Enseñanza Media No 28 de Villa Elisa. ${ }^{58} \mathrm{El}$ mes siguiente protagonizarían un paro de $48 \mathrm{hs}$ en reclamo de la cobertura de auxiliares necesarios para limpieza y atención de los comedores.

${ }^{51} \mathrm{El}$ día 13/6/2013, 14/6/2013. Disponible online en https://goo.gl/XZXBsC

${ }_{52} \mathrm{El}$ día 7/6/2013. Disponible online en https://goo.gl/rsThaU

${ }^{53} \mathrm{El}$ día 7/6/2013. Disponible online en https://goo.gl/9bV4Fd

${ }^{54} \mathrm{El}$ día 30/8/2013. Disponible online en https://goo.gl/9jKNiD

${ }^{55} \mathrm{El}$ día 22/8/2013. Disponible online en https://goo.gl/vB3i9Y

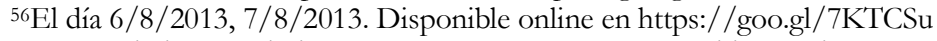

${ }^{57} \mathrm{El}$ día 3/9/2013, 4/9/2013. Disponible online en https://goo.gl/wtDBMd

${ }^{58} \mathrm{El}$ día 4/9/2013. Disponible online en https://goo.gl/mJF6VE 
En octubre de 2013 se anunciaban obras para la Escuela Primaria 30 de Tolosa. Se buscaba acondicionar el deteriorado edificio para la implementación de la jornada extendida. Como se verá durante el año siguiente la escuela se movilizará por las promesas incumplidas de traslado. ${ }^{59}$

\section{Año 2014}

En el año 2014, también se sucedieron decenas de conflictos con escuelas que debieron suspender las clases por problemas vinculados con la infraestructura. El SUTEBA La Plata denunciaba que: "en las escuelas faltan aulas, espacio vital para desarrollar el proceso de enseñanza. Faltan sillas y mesas, faltan baños y faltan libros, porque no hay bibliotecas". El sindicato añadió que: "también como parte de este ajuste económico que afecta a la educación, faltan cargos docentes de maestros, profesores, preceptores y bibliotecarios". ${ }^{60}$ En el marco de la huelga salarial docente que se extendió por 17 días, el reclamo por la mejora de la infraestructura escolar estuvo a la orden del día. ${ }^{61}$ En el marco de la huelga, la Primaria 30 denunciaba la suspensión de las obras en el nuevo edificio que iba a ocupar. A la falta de espacio de la escuela (fundada en la década del sesenta) el temporal del año 2013 había dejado a la escuela con serios problemas edilicios. ${ }^{62}$ En ese momento, la comunidad escolar se había organizado para paliar los problemas más sencillos de resolver. Pero el edificio resultaba insuficiente. Como veremos, meses más tarde la escuela volvería a estar en el candelero. También a principios de marzo, la Escuela de Danzas denunciaba que no se había llevado adelante ningún trabajo para reparar los desperfectos que un incendio había ocasionado a principios de año. ${ }^{63}$

Durante el mes de abril, varias escuelas salieron a la calle para hacer escuchar sus reclamos. La Primaria 30 tenía que mudarse, dada la crisis de su edificio y pasarían a compartirlo con la Primaria 76 que también tenía problemas por el exceso de matrícula. La Secundaria Básica 89 reclamaba por más auxiliares de limpieza y para ello hicieron un corte de calle. Los alumnos manifestaban estar cansados de asumir ellos mismos las tareas de limpieza y cocina en la escuela. ${ }^{64} \mathrm{La}$ Secundaria Básica 37 en una asamblea de padres, docentes y alumnos decidió suspender las clases dadas las condiciones de hacinamiento de los alumnos. ${ }^{65}$ Por su parte, la Escuela Secundaria 65 vio clausurarse su edificio dada el colapso del mismo. Se sucedieron cortes de calles y ocupaciones de la escuela. La Media 1 reclamaba algo tan elemental como agua potable. ${ }^{66}$

En el mes de mayo, docentes, estudiantes y padres se movilizaron y reclamaron por infraestructura, comedores y el pago de sueldos adeudados. La Escuela Tunel era un caso emblemático y en esa movilización el sindicato reclamaba que "cuando consultamos qué empresa era la encargada de refaccionar la tan conocida 'Escuela Tunel' ningún funcionario nos pudo contestar, ya que nadie conocía porque directamente no se había desarrollado la licitación correspondiente". ${ }^{67}$ Previamente durante ese año se habían producido una decena de robos en las escuelas de la región. A fines de mayo, el gobierno de la provincia ponía en conocimiento a los sindicatos docentes de la erogación de partidas presupuestarias extraordinarias para paliar la crisis edilicia. ${ }^{68}$ En ese mes, la Técnica Albert Thomas estuvo

${ }^{59} \mathrm{El}$ día 18/10/2013. Disponible online en https://goo.gl/gSdRwv

${ }^{60}$ Diario Hoy, 25/4/2014.

${ }^{61} \mathrm{El}$ día 20/3/2014. Disponible online en https://goo.gl/8hz3yA

${ }^{62} \mathrm{El}$ día 14/3/2014. Disponible online en https://goo.gl/ij7JPB

${ }^{63} \mathrm{El}$ día 3/3/2014, 4/3/2014. Disponible online en https://goo.gl/Ce7tvs

${ }^{64} \mathrm{El}$ día 13/2/2014, 12/4/2014, 16/4/2014, 18/4/2014, 23/4/2014, 25/4/2014. Disponible online en https://goo.gl/ydy8uM

${ }^{65} \mathrm{El}$ día 21/4/2014. Disponible en https://goo.gl/FeJoRD

${ }^{66} \mathrm{El}$ día 20/4/2014. Disponible en https://goo.gl/mLJnba

${ }^{67}$ Diario Hoy, 22/5/2014.

${ }^{68} \mathrm{El} \mathrm{día} \mathrm{23/5/2014.} \mathrm{Disponible} \mathrm{online} \mathrm{en} \mathrm{https://goo.gl/pY3nFq}$ 
una vez más en el candelero con reclamos similares a los que la habían llevado a la calle en 2006 y $2010 .{ }^{69}$ La cooperadora escolar denunciaba la existencia de obras inconclusas o mal realizadas.

En el mes de junio, varias escuelas se movilizarían ante la falta de calefacción y la suspensión del servicio por parte de la empresa Camuzzi. ${ }^{70}$ Como respuesta, el gobierno erogó una partida especial de 7 millones de pesos a los Consejos Escolares para la compra de artefactos de gas. ${ }^{71}$ De esa suma, solo $429.000 \$$ iban destinados a la Región. También protestarían por las malas condiciones edilicias. Por ejemplo, la Escuela Primaria N 21 de Los Hornos denunciaba que para combatir una invasión de rastas habían llenado de trampas la escuela y la Secundaria $N^{\circ} 26$, de Ringuelet, la reducción de la jornada escolar por falta de agua en los baños durante una semana completa. En ese contexto, un grupo de padres decidió impulsar un blog "mi escuela rota, La Plata" para denunciar con fotos la situación edilicia de la región. ${ }^{72}$ En el marco del recorte por los cupos de comedores, la Escuela Agropecuaria de Abasto decidió movilizarse. Lo hicieron no solo porque esa medida detonante afectaba al $25 \%$ de los estudiantes sino también por la escasez de recursos de toda la escuela: "tiene muchas falencias, como 3 aulas que no se pueden usar por su estado, de modo que se dan clases en el comedor y en la biblioteca; tampoco hay calefacción en varios salones ni mobiliario suficiente, hace años que no envían nada y los chicos se pelean por conseguir un banco y una silla", relataron los padres. Agregaron que los baños eran muy precarios y que faltaba muchas veces combustible indispensable para el trabajo de campo, gasto que terminaba afrontando la cooperadora escolar. ${ }^{73}$ La Media 3, de Berisso, se sumó a las escuelas en la calle reclamando por problemas edilicios. Las escuelas de Arte y de Estética se sumaron a la movilización de la Media 3 y de la Agraria. ${ }^{74} \mathrm{El}$ reclamo también fue llevado a la Dirección de Infraestructura por los sindicatos docentes..$^{75}$

Síntoma del problema extendido, en el mes de julio el Consejo Escolar de La Plata firmó un convenio para que los alumnos de séptimo año de las escuelas técnicas pudieran realizar sus prácticas profesionalizantes haciendo trabajos que requieran otros establecimientos educativos. La iniciativa había sido impulsada por el bloque del Frente Renovador (Massa) con el apoyo del Sindicato de Educadores Técnicos de la República Argentina. ${ }^{76}$ Los sindicatos docentes de las seccionales opositoras (La Plata, La Matanza, Tigre, Bahía Blanca, Quilmes, Berazategui, Ensenada, Marcos Paz y Escobar junto a los maestros Autoconvocados de Malvinas Argentinas y otros distritos) realizaron el día 16 un paro por recomposición salarial y "condiciones de trabajo apropiadas, en establecimientos con la infraestructura y mantenimiento aptos para que se desarrolle el proceso de enseñanza-aprendizaje". ${ }^{77}$ En ese marco, se definió también el paro de $48 \mathrm{hs}$ posterior al receso escolar. ${ }^{78}$

Durante el mes de agosto, luego del receso escolar, el sindicato docente convocó a una medida de fuerza por $48 \mathrm{hs}$ para el 4 y el 5 de ese mes. Además de recomposición salarial a partir de la activación de la cláusula de monitoreo salarial, los docentes reclamaban por la situación de infraestructura en la provincia. El compromiso oficial luego de la protesta fue el destinar 45 millones de pesos para construir en un plazo de entre 90 y 100 días y 140 nuevas aulas en 15 de los distritos más necesitados. Los problemas edilicios aparecían como uno de los reclamos prioritarios de los docentes. En particular, el gobierno se comprometió a desarrollar el Fondo Escuela luego de la huelga, una caja chica para reparaciones y

${ }^{69} \mathrm{El}$ día 22/5/2014. Disponible online en https://goo.gl/irpVxu

${ }^{70}$ Diario Hoy, 14/6/2014.

${ }^{71} \mathrm{El}$ día 5/6/2014, 6/6/2014. Disponible online en https://goo.gl/L6P7GB

${ }^{72} \mathrm{El}$ día 24/6/2014, 25/6/2014. Disponible online en https://goo.gl/4w2v17

${ }^{73} \mathrm{El}$ día 21/6/2014. Disponible online en https://goo.gl/eCbpEQ

${ }^{74} \mathrm{El}$ día 6/6/2014, 11/6/2014. Disponible online en https://goo.gl/T135Qf

${ }^{75} \mathrm{El}$ día 10/6/2014. Disponible online en https://goo.gl/PRjNpM

${ }^{76} \mathrm{El}$ día 19/7/2014. Disponible online en https://goo.gl/Fvuw8u

${ }^{77} \mathrm{El}$ día 16/7/2014. Disponible en https://goo.gl/w3Fqqx

${ }^{78} \mathrm{El}$ día 11/7/2014, 13/7/2014. Disponible en https://goo.gl/RhwLaR 
mantenimiento que en diciembre de ese año se denunciaría insuficiente. Además, se reclamaba por el compromiso de que el 50\% del Fondo de Financiamiento Educativo que llegara a las intendencias sea destinado a infraestructura escolar. ${ }^{79}$

A fines de octubre, se denunció la caída de un techo producto de una tormenta que afectó aún más una situación ya estructural en el Instituto de Formación Docente $\mathrm{N}^{\circ}$ 8. La Escuela Técnica $\mathrm{N}^{\circ} 9$ también suspendió preventivamente las clases. La situación de ambas escuelas actualizó una vieja problemática: en el mes de abril, el Consejo Escolar asumía un gasto por 2,1 millones de pesos, cifra que era reconocida insuficiente por dicho organismo y que solo alcanzaría para intervenir sobre 33 de los 309 edificios escolares platenses. ${ }^{80}$ Algo similar ocurrió con la Escuela Secundaria No 15 cuyo edificio sufrió inundaciones y con la Escuela Primaria $\mathrm{N}^{\circ} 80$ luego de la voladura de sus techos como resultado de un temporal. También durante el mes de octubre, un grupo de padres realizó un piquete en el Anexo de la Escuela Secundaria No 11 de Tolosa reclamando por la reubicación de la escuela en un nuevo edificio. ${ }^{81}$

En el mes de noviembre, la Escuela $\mathrm{N}^{\circ} 37$ de Arana se movilizó nuevamente para que la Dirección General de Cultura y Educación cumpliera con una larga lista de demandas. Inclusive, en una asamblea, un grupo de padres decidió que no se iniciaría el ciclo lectivo 2015 si no se garantizaba la resolución de los problemas más inmediatos. Además de la construcción de un edificio propio para la secundaria (en el mismo edificio convivía una escuela primaria, un jardín de infantes y el equivalente al tercer ciclo básico) reclamaban la reparación integral de los baños y el camino de acceso a la escuela. Los delegados docentes denunciaban que al Anexo se accedía por un camino de 30 metros de barro lo que obligaba a suspender las clases cada lluvia. ${ }^{82}$

En diciembre de 2014, la Asociación Civil Alere estimaba que en la Ciudad de La Plata hacían falta 73 jardines con 7 secciones cada uno para la población comprendida en la franja 3 a 5 para garantizar la cobertura completa del nivel. Que faltaban plazas para los niños de 4 era reconocido oficialmente. También que ese déficit no lograba ser cubierto por el circuito privado que se encontraba saturado, en su techo de cobertura. ${ }^{83} \mathrm{La}$ Asociación estimaba que el circuito público contaba con 87 establecimientos y se requería casi duplicar la oferta para garantizar la cobertura total. Dentro de la Región, las zonas más críticas eran "Los Hornos, Romero, Villa Elvira, Altos de San Lorenzo y Abasto. Mientras tanto, se dieron a conocer obras de reparación en la Escuela Técnica $\mathrm{N}^{\mathrm{o}} 2$ de Ensenada. ${ }^{84}$ También el problema de infraestructura apareció en varias movilizaciones docentes durante los meses de octubre, noviembre y diciembre anticipando la discusión paritaria de $2015 .{ }^{85}$ Ese año también se sucedieron una numerosa cantidad de hechos vandálicos que afectaron a numerosas escuelas y también se produjeron movilizaciones por recortes en los cupos de los comedores escolares.

\footnotetext{
${ }^{79} \mathrm{El}$ día 9/7/2014, 30/7/2014, 4/8/2014, 5/8/2017, 6/8/2014. Disponible online en https://goo.gl/vtKCt1

${ }^{80} \mathrm{El}$ día 31/10/2014. Disponible en https://goo.gl/4uZHaQ

${ }^{81} \mathrm{El}$ día 7/10/2014, 8/10/2014. Disponible en https://goo.gl/WchQF2

${ }^{82} \mathrm{El}$ día 9/11/2014. Disponible en https://goo.gl/1F7JwR

${ }^{83} \mathrm{El}$ día 28/12/2014. Disponible en https://www.eldia.com/nota/2014-12-28-en-nuestra-region-no-hay-jardines-de-infantespara-todos. Para ver los límites de la privatización educativa en Argentina, para esta etapa entre otros trabajos puede consultarse De Luca, R. $\left(2017^{\mathrm{a}}\right)$. Para una tesis contraria: Narodowski, Mariano \& Moschetti, Mauro, "The growth of private education in Argentina: evidence and explanations", Compare: A Journal of Comparative and International Education, 45(1), Gran Bretaña, 2015a, 47-69; Narodowski, Mariano y Moschetti, Mauro, "Why does private school enrollment grow? Evidence from Argentina", Cogent Education, 2(1), Oxford, 2015b. Disponible en:

https://www.tandfonline.com/doi/full/10.1080/2331186X.2015.1077604

${ }^{84} \mathrm{El}$ día 19/12/2014. Disponible en https://www.eldia.com/nota/2014-12-19-inauguraron-refacciones-en-la-escuela-tecnica-n2

${ }^{85} \mathrm{El}$ día 15/10/2014, 4/11/2014, 10/11/2014, 4/12/2014. Disponible en https://goo.gl/ybB1fN
} 


\begin{abstract}
Año 2015
En el 2015, una vez más los Institutos de Formación Docente se encontraron movilizados y en la calle. La comunidad educativa se encontraba movilizada desde el mes de abril y en junio decidió organizar una marcha reclamando por el edificio que ya había sido prometido en 2011. En el mes de junio, el instituto convergió en una marcha con otras escuelas de la Región, todas reclamando por infraestructura. En efecto, los más de 2.000 estudiantes y docentes afectados lograron articular la movilización sumando distintas escuelas que se solidarizaban con los reclamos del Instituto y agregaban los propios. ${ }^{86}$ Volanteadas con vecinos, cortes de calle, protestas en el interior de las escuelas fueron algunas de las medidas registradas como acciones simultáneas en nueve puntos de la región incluyendo la ciudad capital y City Bell. ${ }^{87}$ La Media 21, la Secundaria 37, la Escuela de Teatro, la Escuela Media 25, la Primaria 67 y la Secundaria 57 del barrio Los Porteños de City Bell, la Escuela Secundaria 37 de Gorina, la Secundaria 43 de Villa Garibaldi fueron algunas de las escuelas que participaron de la protesta. ${ }^{8} \mathrm{La}$ convergencia de una decena de escuelas se repitió a fines de junio. ${ }^{89}$ En paralelo, días más tarde, se denunciaría una sub-ejecución del gasto en materia de infraestructura: se estimaba que sobre un total de 31 millones, apenas se habían destinado 1 millón a equipamiento. ${ }^{90}$ En ese cuadro, otras escuelas realizaban "piquetes" 91 por la falta de calefacción y de estufas. En efecto, adolescentes de la Secundaria $\mathrm{N}^{\circ} 65$ de diagonal 73 y 28 y los de la $\mathrm{N}^{\circ} 22$ de La Granja apelaron a la quema de gomas y maderas para cortar el paso en arterias claves a los fines de hacer visible su reclamo. ${ }^{92}$ Acciones similares realizó la Escuela 57 de City Bell. ${ }^{3}$ Durante los primeros días de mayo y hasta la gran marcha a fines de junio, esas escuelas realizaron distintas protestas con un común denominador: la crisis de infraestructura. ${ }^{94}$

En el mes de febrero, se anunció la segunda etapa de obras en la Escuela Secundaria $N^{0} 16$, escuela que había estado en conflicto años anteriores. ${ }^{95}$ También prometían que, para abril, la Escuela Secundaria 57 contaría con un edificio propio. ${ }^{96} \mathrm{El}$ Gobierno proyectaba obras en 23 escuelas a lo largo de todo el año por una suma de 128 millones de pesos. ${ }^{97} \mathrm{La}$ Técnica 9, la Escuela Primaria $\mathrm{N}^{\circ}$ 30, la Primaria $\mathrm{N}^{\circ} 117$, el Jardín de Infantes $\mathrm{N}^{\circ} 950$ y la Secundaria $\mathrm{N}^{\circ} 31$ eran algunas de las escuelas comprendidas en e plan.

En el mes de abril, dos escuelas semirrurales denunciaban la falta de servicios elementales, como el teléfono, y el hundimiento de patios, falta de aulas, hacinamiento. La protesta alcanzó además de a las escuelas Primaria $N^{\circ} 6$ y Secundaria $N^{\circ} 41$ a dos escuelas de City Bell: la Primaria $N^{\circ} 67$ y la Secundaria $\mathrm{N}^{\circ} 57$, del barrio Los Porteños. Allí directamente los padres decidieron realizar un corte de calles "hartos de tanta desidia" como relataban. ${ }^{98}$
\end{abstract}

86Diario Hoy, $11 / 6 / 2015$.

${ }^{87}$ El día, 4/6/2015, 11/6/2015, 12/6/2015. Disponible en https://goo.gl/4CVWsF

${ }^{88} \mathrm{El}$ día, 10/6/2015. Disponible en https://goo.gl/o8N1X2

89Diario Hoy, 30/6/2015.

${ }^{90}$ Diario Hoy, 15/7/2015.

${ }^{91} \mathrm{El}$ término refiere al corte de calles prolongado.

${ }^{92}$ El día,16/5/2015, 24/6/2015, 25/6/2015. Disponible online en https://goo.gl/GYF9F4

${ }^{93}$ El día,15/5/2015. Disponible online en https://goo.gl/N961Eq

${ }^{94}$ Desde el 6 de mayo se registran acciones en el Diario El día realizadas por algunas de las escuelas detalladas en ese párrafo.

${ }^{95} \mathrm{El}$ día, 6/2/2015, 12/2/2015. Disponible online en https://www.eldia.com/nota/2015-2-12-renovado-edificio-para-laescuela-secundaria-16

96El día, 10/2/2015. Disponible online en https://www.eldia.com/nota/2015-2-10-secundaria-57-de-villa-elisa-estrenaraedificio-en-abril

${ }^{97}$ El día,3/2/2015. Disponible online en https://www.eldia.com/nota/2015-2-3-salen-a-arreglar-escuelas-tras-fuertes-reclamosde-los-padres

${ }^{98}$ El día 24/4/2015, 25/42015. Disponible online en https://goo.gl/YQejzt 
En el mes de mayo, previo al gran conflicto de junio, el Municipio declaraba obras de mantenimiento, puesta en valor, desmalezamiento y reparación de fachadas y veredas en la Escuela $\mathrm{N}^{\circ}$ 22 de Altos de San Lorenzo, el colegio “Albert Thomas" (Técnica 6) y la Escuela Media N 15 de City Bell. ${ }^{99}$

En el mes de agosto, el Normal 1 sufrió el desprendimiento del cielorraso de diez aulas luego de una tormenta. La comunidad educativa denunciaba que el estado de abandono del edificio era crónico. Luego de una semana con el mismo problema, un grupo de padres identificaba claramente el problema y declaraban: "en esta reunión queremos que las autoridades nos expliquen porque todavía no comenzaron a refaccionar nada y que nos den un argumento sólido y preciso. Nosotros ya tenemos decidido y lo charlamos con los centros de estudiantes, que, si las aulas siguen cerradas y no se arreglan, no vamos a mandar a los chicos al colegio y el resto de la escuela estaría dispuesto a parar también". Y los detalles seguían con datos de otras escuelas recabados por el SOEME: "tenemos todo documentado con fotografías. Las irregularidades son tremendas. Presencia de alimañas (ratas, ratones, arañas, cucarachas), hongos y humedad en las paredes y techos, goteras, pérdidas de gas en termotanques, calefones y cocinas, pozos ciegos desbordados, cañerías tapadas, aguas servidas (contaminadas con restos fecales y orina) en baños y cocinas, heladeras rotas que provocan que los alimentos pierdan la cadena de frío y hasta el peligro inminente de derrumbe de cielorrasos o paredes, entre otras". Como si ello fuera poco, agregaban: "hay cables pelados a la vista que son un peligro inminente para los trabajadores y los chicos. Además, faltan luminarias, y esto conlleva problemas de inseguridad. A la noche varios de los edificios escolares quedan en la más absoluta obscuridad y en ocasiones sufren actos vandálicos". Junto al Normal 1, se movilizaron una serie de escuelas que arrastraban problemas de infraestructura: la Escuela Secundaria Básica No 37 y la Escuela Secundaria No 7 de Arturo Seguí. ${ }^{100}$ Junto a ellas marcharon la Secundaria 46, la Escuela Secundaria Básica No 38, la Agraria de Ruta 36, la Secundaria Básica No 27, la Secundaria Básica No 49, la Secundaria Básica No 26, la Secundaria Básica No 39, la Secundaria Básica No 24, la Secundaria Básica No 38 y la Secundaria 45. El mapa de riesgo edilicio que se presentaría a las autoridades incluía a la Escuela de Teatro, la Secundaria 54, la Secundaria 38, la Media 21, la Secundaria 43, la Primaria 37, la Media 7, la Secundaria 57, el Instituto de Formación Docente No 9 y la Media 25. Construcción de aulas, de bibliotecas, de gabinetes, falta de servicios básicos (agua, luz, teléfono), falta de mantenimiento eran algunos de los problemas más comunes que unificaban el reclamo. El SUTEBA La Plata apoyó la movilización de las escuelas y marchó desde Plaza Moreno hasta la Dirección General de Escuelas. ${ }^{101}$ La mayoría de ese grupo de escuelas contaba con una prehistoria de lucha. A fines de junio, diez de esas comunidades educativas se habían movilizado reclamando la resolución de los problemas de infraestructura. En esa oportunidad, alumnos, docentes y padres se reunieron con autoridades oficiales durante cinco horas. En esa ocasión, entre otras, participaron el Instituto Superior de Formación Docente $N^{\circ}$ 9, la Media $N^{\circ} 25$ (2 y 54), la Media $N^{\circ} 21$ (36, 2 y 3), la Secundaria 57 y la Primaria 67 de City Bell, la Escuela de Teatro de La Plata, la Secundaria 37 de Gorina, la Primaria 37 (2 y 45), la Secundaria 43 de Villa Garibaldi, la Secundaria 54 (120 y 604), la Secundaria 7 de Arturo Seguí y la ESB 37 de Arana. ${ }^{102}$ Los compromisos oficiales asumidos incluían la construcción de aulas, la resolución de cuestiones relacionadas a calefacción, instalaciones eléctricas, equipamiento de aulas y además se autorizaba la inmediata creación de cargos faltantes. Previo a la reunión, las comunidades educativas se habían movilizado desde Plaza Moreno a la Dirección General de Cultura y Educación. El

${ }^{99}$ El día 25/5/2015. Disponible online en https://goo.gl/LtHfLQ

100 El día ,28/8/2015, 29-8-2015. La nota periodística destaca que de la movilización participaron una veintena de escuelas. Disponible online en https://goo.gl/GhLdHC

101El dia, 20/8/2015, 21/8/2015, 22/8/2015, 24/8/2015, 25-8-2015. Disponible online en https://goo.gl/81uRuh

${ }^{102}$ El día, 26/6/2015, 30/6/2015, 1/78/2015. Disponible online en https://goo.gl/bRFn1Q 
11 de junio ya se habían protestado a la vera de cada escuela en conflicto familias, alumnos y docentes. Que el conflicto resurgiera en agosto evidenciaba los límites de la respuesta oficial.

Por su parte, la Escuela Media $\mathrm{N}^{\circ} 21$ reclamaba por un edificio propio desde principios de año cuando empezó a funcionar en dos sedes distintas. La escuela ya estaba acostumbrada a funcionar en una sede no propia. Desde 1988 funcionaba en UPCN, el sindicato de estatales. ${ }^{103}$

La protesta de la comunidad educativa validaba uno de los déficits que describimos en base a la información censal: "la mayoría de las escuelas en la ciudad de La Plata, tanto de gestión pública como privada, son inaccesibles para las personas con discapacidad debido a las múltiples barreras físicas que presentan”. Por tal motivo, la ONG “Acceso ya” decidió iniciar una demanda a la Dirección General de Cultura y Educación. Según la demanda, de los poco más de 400 establecimientos educativos que funcionaban en la Ciudad, esto es jardines, escuelas primarias y secundarias públicas y privadas, comunes y especiales, en base a un muestro de 154 centros, las conclusiones no dejaban lugar a dudas: "sólo un $1 \%$ de los establecimientos educativos es accesible, un $84 \%$ es inaccesible, y un $15 \%$ no pudo determinarse ya que las autoridades de las escuelas, pese a tener permiso firmado por la Inspectora Jefe Distrital de La Plata, se negaron a permitir el acceso al edificio". 104

En el mes de octubre, las familias de la zona de Abasto se organizaban para reiterar un viejo reclamo: la construcción de una escuela para el nivel inicial ya que un solo jardín debía absorber toda la demanda de la zona. Desde 2006 reclamaban por un nuevo edificio que ya tenía asignado un terreno para la construcción desde diciembre de 2014. ${ }^{105}$ También ese mes se "inauguró" el Jardín de Infantes № 950. El mismo dado los problemas en el viejo edificio venía funcionando en un galpón. Pero la inauguración de la nueva sede estuvo lejos de resolver los problemas: el edificio "nuevo" no contaba ni con luz, agua ni gas. Hartos, los padres intentaron tomar el edificio situación que fue impedida por un fiscal. ${ }^{106}$ También se produjo una nueva movilización del Centro de Educación Complementaria $\mathrm{N}^{\circ} 803$ de Punta Lara que hacía meses reclamaba por un nuevo edificio. En esa oportunidad, lo hizo junto al SUTEBA Ensenada y SUTEBA La Plata. ${ }^{107} \mathrm{La}$ falta de inversión en infraestructura era indicada por los sindicatos y la comunidad escolar como la gran causante de que los alumnos del CEC 803 no contaran con un edificio propio. Como vimos, no se trataba de la única escuela en esa condición.

En el mes de noviembre, la Escuela Primaria No 8 "Domingo F. Sarmiento" reclamaba por reparaciones en su edificio. Los padres denunciaban que hacía un año que los baños de la escuela no funcionaban apropiadamente y los alumnos "tenían que aguantarse" para no usarlos. A ese cuadro se agregaban desprendimientos del techo y problemas en los pisos. Como si eso fuera poco, la instalación eléctrica registraba fallas graves que ponían en peligro a los alumnos mismos. Como medida que acompañaba a la protesta, los padres elevaron un petitorio ante la Dirección General de Escuelas. ${ }^{108}$

Finalmente, en diciembre de 2015 se evaluaría declarar la emergencia edilicia en toda la provincia. El sindicato exigía, en el marco de la discusión futura de la paritaria, que se mejorara la infraestructura escolar. ${ }^{109}$

$\mathrm{Al}$ inicio de la gestión de Cambiemos y la presidencia de Mauricio Macri y la gobernación de María Eugenia Vidal, en el 2016, se reconocía que "de los 11.213 edificios escolares de la provincia, el 80 por ciento "tiene problemas de diversa índole" según admitió Alejandro Finocchiaro. ${ }^{110}$

103 El día, 18-12-2015. Disponible online en: https://goo.gl/FEmnkj

104 El dia, 27/11/2015, 28-11-2015. Disponible online en https://goo.gl/1e8e25

105El día, 9/9/2015, 10/9/2015, 31/10/2015, 28-11-2015. Disponible online en https://goo.gl/qSGeKG

106 El día, 29/10/2015, 28-11-2015. Disponible online en https://goo.gl/BnkvNC

${ }^{107} \mathrm{El}$ día, 16/10/2015. Disponible online en https://goo.gl/EDdt78

${ }^{108} \mathrm{El}$ día, 16/11/2015, 17-11-2015. Disponible online en: https://goo.gl/tuvw7j

${ }^{109} \mathrm{El}$ día, 24-12-2015. Disponible online en: https://goo.gl/iSQwTQ

${ }^{110}$ Infocielo, 8/11/2016. Disponible online en: 


\section{Conclusiones provisorias}

El presente trabajo recoge una primera aproximación al problema de las luchas protagonizadas por la comunidad educativa (docentes, padres, alumnos, auxiliares) por problemas vinculados infraestructura escolar en una alianza circunstancial que, a menudo, incluye también a los directores de las escuelas y a docentes delegados del Sindicato. A menudo, el sindicato centralmente durante el período en que la conducción estuvo a cargo del frente multicolor impulsó distintas acciones acompañando a la alianza de docentes, alumnos y padres en lucha. Como se dijo, se trata de un abordaje poco transitado ya que la mayoría de los trabajos se centran en la lucha salarial protagonizada por los docentes. Con esto no se afirma que ambas luchas no guarden conexión. En otros trabajos, hemos mostrado para el caso de La Matanza que la lucha por la infraestructura escolar era encarada por los docentes en conexión con la lucha salarial. La expresión particular de esa conexión era la lucha por pluses salariales vinculados a la desfavorabilidad de la zona donde se emplazaban las escuelas (De Luca, 2017c).

En el período de referencia hemos contabilizado más 130 acciones protagonizadas por la comunidad escolar (padres, alumnos junto a docentes) reclamando por mejoras en las condiciones de infraestructura: reemplazo de edificios, reparaciones en techos, paredes, baños, dotación de más aulas, por la prestación de servicios básicos como luz, agua y gas son algunos de los conflictos más salientes. Eso sin considerar las acciones vinculadas al agravamiento de una condición de déficit estructural por distintos fenómenos meteorológicos tal como ocurrió en 2012 y 2013 centralmente. Dentro de las acciones desplegadas, el corte de calles y los piquetes adquirieron centralidad junto a movilizaciones a sedes oficiales (Jefaturas, Consejo Escolar, o a la sede central de la Dirección General de Cultura y Educación). En materia de organización y de lucha de la comunidad se mostró como se reclamaba centralmente por: aumento del presupuesto, obras, nuevas escuelas y secciones, reparación de las escuelas existentes, escuelas que incluyan áreas de administración (para preceptorías, para personal directivo). En varias ocasiones, el sindicato local de La Plata reclamó por mayor y mejor calidad edilicia en la discusión paritaria y la dotación de todo el personal docente y no docente necesario para el funcionamiento de las escuelas.

En esta primera aproximación se pudo ver que el problema de la infraestructura vertebra, en general, toda una serie de reclamos de la comunidad escolar. En esa lucha, se pliegan docentes y sus estructuras sindicales, pero no son los únicos actores del proceso. La comunidad participa, en ocasiones acompañada por delegados, y busca respuestas para un problema real y cotidiano de las escuelas en la Región. En general, se imponen métodos de acción directa, como se dijo anteriormente, y en general la prensa platense elige hablar de "piquetes de mochilas". En efecto, movilizaciones, caravanas, asambleas, tomas de escuela, recolección de firmas, petitorios son algunos de los métodos de lucha utilizados. En general, en un estudio preliminar para el caso platense para el período 2003-2007 hallamos que la protesta derivaba en mayores partidas presupuestarias para infraestructura ampliándose los créditos del BID y asignándose nuevas partidas y la misma tendencia pareciera verificarse en particular para los años 2012, 2013 y 2014. Además del sindicato, otros organismos participan en el relevamiento de las condiciones de infraestructura escolar: Organizaciones no gubernamentales y la Universidad de La Plata producen insumos que permiten conocer el deterioro edilicio.

Lejos de ser un aspecto menor, el problema de la infraestructura es relevante en la Región y también emergió con centralidad en los estudios realizados en otras jurisdicciones (valgan los casos de las provincias de Salta, Misiones, Formosa, Chaco, así como en otros distritos trabajados de la provincia

http://infocielo.com/nota/74679/escuelas en emergencia lanzan una web para denunciar problemas edilicios y reclama robras/ 
de Buenos Aires como es el caso de La Matanza). Se considera que el déficit de infraestructura se agrava en contextos de aumento de la obligatoriedad escolar. Tanto en 1994-98 como en 2014 (operativo CENIE 09), la infraestructura de la provincia se encontraba estancada. Peor aún. En contextos de expansión de la matrícula, aumenta la concentración de alumnos por escuela. De allí que varias de las acciones relevadas narraban situaciones de hacinamiento escolar. Si bien no nos ocupamos de esto aquí, dejamos sentado que para el nivel medio y el inicial el Estado generó otras formas de "desagote": de las escuelas modalidad común a la de adultos y de allí a las formas de terminalidad exprés tipo Fines 2 que ofrecen una vía rápida para cursar el secundario en sedes no escolares (De Luca, 2017) o la ampliación de la gestión comunitaria en particular para el nivel inicial.

\section{Bibliografía y fuentes}

Aiziczon, Fernando, Dilemas político-organizativos del sindicalismo docente. El caso de ATEN durante la primera mitad de la década de los "90", FAVARO, Orietta (Comp.) El arcón de la bistoria reciente en la norpatagonia argentina, Buenos Aires, Biblos, 2010, 120-149.

Aiziczon, Fernando, "Tras las huellas del cutralcazo Una lectura desde el sindicato docente ATEN", Estudios, N² 26, Córdoba, UNC, Julio-Diciembre 2011, 95-110.

Aiziczon, Fernando, "Maestros, sindicatos, rutas y puebladas: los docentes neuquinos en el Cutralcazo", Educação, v. 14 (1), Marilia, jan/jun 2013, 21 -36.

Auyero, Javier, La protesta. retratos de la beligerancia popular en la Argentina democrática, Buenos Aires, Universidad de Buenos Aires, 2002.

Benclowicz, José, Estado de malestar y tradiciones de lucha. Genealogía del movimiento piquetero de Tartagal-Mosconi, Buenos Aires, Rumbos, 2013.

Boletín Oficial de la provincia de Buenos Aires, AÑO CIII. Número 26.983, La Plata, 7de enero de 2013. Boletín Oficial de la provincia de Buenos Aires, AÑO CVI. Número 27.590, La Plata, 3 de agosto de 2015.

Boletín Oficial de la provincia de Buenos Aires, AÑO CVI. Número 27.659, La Plata, 10 de noviembre de 2015.

Chiappe, Mercedes y Spaltenberg, Ricardo, "Una aproximación a los conflictos laborales del sector docente en Argentina durante el período 2006-2009”, Associações e Sindicatos de Trabalhadores em Educação. Seminário Internacional da Rede de Pesquisadores sobre Associativismo e Sindicalismo dos Trabalhadores em Educação, Rio de Janeiro, 22 e 23 de abril de 2010, 1-25.

De Luca, Romina, Brutos y Baratos. Descentralización y privatización en la educación argentina (19552001). Edición aumentada y ampliada, Buenos Aires, Ediciones RyR, 2017a.

De Luca, Romina, "La izquierda en docentes. Entre el crecimiento de la Multicolor y el seguimiento a la celeste”, Razón y Revolución, Número 30, Buenos Aires, Ediciones RyR, 2017b, 73-104.

De Luca, Romina: "El lado B del presupuesto educativo: conflictos por comedores e infraestructura en las Regiones I y III de la provincia de Buenos Aires, años 2003 y 2015" Mesa 80, XVI Jornadas Interescuelas/Departamentos de Historia Mar del Plata, 9 al 11 de agosto de 2017.

De Luca, Romina, "La crisis crónica de las escuelas. Conflictos socioeducativos y la lucha por la infraestructura escolar en la Region I durante la presidencia de Néstor Kirchner (La Plata, Berisso, Ensenada, Brandsen, Magdalena y Punta Indio, 2003-2007)", XI Jornadas de Economía Crítica, Santa Fe, Facultad de Ciencias Económicas, Universidad Nacional del Litoral, 6, 7 y 8 de septiembre de 2018. DINIECE, Censo Nacional de Infraestructura Escolar. Los edificios escolares del país en 1998 Resultados definitivos del CENIE 98, Buenos Aires, Ministerio de Educación, diciembre de 2004.

Diario El economista, 6/8/2018. 
Diario El Día. Años 2011 a 2015.

Diario Hoy. Años 2011 a 2015.

Dirección General de Cultura y Educación Dirección Provincial de Planeamiento Dirección de Información y Estadística Departamento Procesamiento de Datos, Matrícula y unidades educativas totales por Distrito, según sector. Serie 2007-2016, Buenos Aires, Argentina, 2017.

Dirección General de Cultura y Educación-Dirección Provincial de Planeamiento Dirección de Información y Estadística, Descifrando la Región 31, Buenos Aires. Disponible online en: https://goo.gl/Rn5euc

Dirección General de Cultura y Educación, Plan de obras 2010-2011. $3^{\circ}$ Publicación de llamado a licitación pública Disposición No 00184/2011, Buenos Aires, 2010.

Dirección General de Cultura y Educación, Plan de obras 2012. Llamado a licitación pública. Disposición $N^{o}$ 0004/2012, Buenos Aires, 2012.

Dirección General de Cultura y Educación-Dirección Provincial de Infraestructura Escolar, Plan de obras 2012. Llamado a Licitación Pública. Disposición No0045/2012, Buenos Aires, 2012.

Dirección General de Cultura y Educación - Dirección Provincial de Infraestructura Escolar, Plan de obras 2012. Llamado a Licitación Pública. Disposición No0025/2012, Buenos Aires, 2012.

Dirección Provincial de Infraestructura Escolar, Pliego de Obras 2010, Buenos Aires, 2011.

Farinetti, Marina, “¿Qué queda del "movimiento obrero"? Las formas del reclamo laboral en la nueva democracia argentina", Trabajo y Sociedad , 1 (1), Buenos Aires, 1999. Disponible online en: http://www.unse.edu.ar/trabajoysociedad/Zmarina.htm

Gindin, Julián, "Sindicalismo docente en México, Brasil y Argentina: una hipótesis explicativa de su estructuración diferenciada", Revista mexicana de investigación educativa, 13(37), México DF, 2008, 351-375.

Gindin, Julián y Soul, Julia, "Políticas de organización gremial en Rosario. Apuntes sobre experiencias docentes y mercantiles" Ponencia presentada en el 6to Congreso Nacional sobre estudios de trabajo: Los trabajadores y el trabajo en crisis, Buenos Aires, 2003.

Legarralde, Martín y Perazza, Roxana, Los sindicatos y la educación pública en América Latina. El sindicalismo docente en la Argentina, Buenos Aires, Konrad, 2007.

LOYO, Aurora, "Los sindicatos docentes en América Latina: entre la lógica laboral y la lógica profesional”, Profesión docente/ Profissão docente (25). Río de Janeiro, Enero-Abril, 2001, 65-81.

Ministerio de Educación, Dirección de Infraestructura Dirección General de Cultura y Educación UEPPFE Unidad Ejecutora Provincial de Programas con Financiamiento Externo, Plan de Obras. Licitación Pública $N^{\circ} 8 / 13$, Buenos Aires, 2013,

Ministerio de Educación, Censo Nacional de Infraestructura Escolar. Jurisdicción Buenos Aires, 30 de marzo de 2017. Informes disponibles en: http://cenie.educ.ar/

Migliavacca, Adriana, La protesta docente en la década de 1990, Buenos Aires, Baudino Ediciones, 2011.

Migliavacca, Adriana, "Experiencias de organización en el ámbito sindical docente. Interrogantes y

desafíos para la construcción del clasismo”, Polifonías. Revista de Educación, Año II (3), Luján, UNLU, 2013, 65-84.

Narodowski, Mariano \& Moschetti, Mauro, "The growth of private education in Argentina: evidence and explanations", Compare: A Journal of Comparative and International Education, 45(1), Gran Bretaña, 2015a, 4769.

Narodowski, Mariano y Moschetti, Mauro, "Why does private school enrollment grow? Evidence from Argentina”, Cogent Education, 2(1), Oxford, 2015b. Disponible en:

https://www.tandfonline.com/doi/full/10.1080/2331186X.2015.1077604

Palamidessi, Mariano, "Sindicatos docentes y gobiernos: Conflictos y diálogos en torno a la Reforma Educativa en América Latina”, Revista Paraguaya de Sociología, 40(117), 9, Asunción, 2003, pp. 1-35. 
Palamidessi, Mariano y Legarralde, Martín, "Sindicalismo docente, gobiernos y reformas educativas en América Latina y el Caribe: Condiciones para el diálogo", Diálogo Regional de Política - Red de Educación, InterAmerican Development Bank, 2006, 1-62.

Petruccelli, Ariel, Docentes y piqueteros: De la buelga de ATEN a la pueblada de Cutral Có, Buenos Aires, Ediciones El Cielo por Asalto, 2005.

Petruccelli, Ariel, Las maestras piqueteras, Buenos Aires, El cielo por asalto, 2008.

Rivas, Axel y Dborkin, Daniela, “QQué cambió en el financiamiento educativo en Argentina?”, Documento de Trabajo No 162, Buenos Aires, CIPPEC, febrero de 2018, 1-57.

Sanz Cerbino, Gonzalo, Cupable. República Cromañón, 30 de diciembre de 2007, Buenos Aires, Ediciones RyR, 2009.

Sartelli, Eduardo, La plaza es nuestra: el Argentinazo a la luz de la lucha de la clase obrera en la Argentina del siglo XX. Buenos Aires, Ediciones RyR, 2007.

Sartelli, Eduardo, (Dir.), Patrones en la ruta. El conflicto agrario y los enfrentamientos en el seno de la burguesía, marzojulio de 2008, Ediciones RyR, 2008.

Sartelli, Eduardo (Comp.), La crisis orgánica de la sociedad argentina, Buenos Aires, EFFL Universidad de Buenos Aires, 2011.

Sartelli, Eduardo, "El origen del "relato". La ideología bonapartista del kirchnerismo como emergencia de un momento de la vida social argentina", Sartelli, Eduardo y Kabat, Marina (coord.), Mentiras verdaderas. Ideologia, nacionalismo y represión en Argentina (1916-2015). Buenos Aires, EFFL, 217, 283-307.

Sartelli, Eduardo, De Luca, Romina, et. all, "Una mirada histórica sobre la evolución del salario docente, desde la década del 30" hasta la actualidad", XXXVII Encuentros de Geohistoria Regional, Posadas, Facultad de Humanidades y Ciencias Sociales de la Universidad Nacional de Misiones, 11, 12 y 13 de octubre del 2017.

Sartelli, Eduardo, Harari Ianina y Villanova Nicolás, "Radiografía de la estructura laboral tras los gobiernos kirchneristas", Revista Kairos, Ecuador, en prensa.

Suárez, María Eugenia, "Procesos identitarios en las Acciones Colectivas: Etnografía de los Docentes Autoconvocados en Salta", IX Congreso Argentino de Antropología Social. Facultad de Humanidades y Ciencias Sociales, Posadas, Universidad Nacional de Misiones, 2008, 1-22.

Schulman, José, La Rioja que resiste. Educación y lucha de clases. Historia de la Asociación de Maestros y Profesores de La Rioja, Rosario, Ediciones AMP, 2002.

TECHO Argentina, Relevamiento de asentamientos informales. Año 2013, Buenos Aires, Techo, noviembre de 2013.

Vázquez, Silvia, "Paritarias: conquista y derecho de los trabajadores", Cuadernos de formación Sindical, Buenos Aires, Secretaria de Educación, 2005. 